\title{
Assessing the Costs and Benefits of Resilience Investments: Tennessee Valley Authority Case Study
}

Approved for public release.

Melissa Allen

Thomas J. Wilbanks Benjamin L. Preston Shih-Chieh Kao James Bradbury Distribution is unlimited.

January 2017 


\title{
DOCUMENT AVAILABILITY
}

Reports produced after January 1, 1996, are generally available free via US Department of Energy (DOE) SciTech Connect.

Website http://www.osti.gov/scitech/

Reports produced before January 1, 1996, may be purchased by members of the public from the following source:

\author{
National Technical Information Service \\ 5285 Port Royal Road \\ Springfield, VA 22161 \\ Telephone 703-605-6000 (1-800-553-6847) \\ TDD 703-487-4639 \\ Fax 703-605-6900 \\ E-mail info@ntis.gov \\ Website http://classic.ntis.gov/
}

Reports are available to DOE employees, DOE contractors, Energy Technology Data Exchange representatives, and International Nuclear Information System representatives from the following source:

Office of Scientific and Technical Information

PO Box 62

Oak Ridge, TN 37831

Telephone 865-576-8401

Fax 865-576-5728

E-mail reports@osti.gov

Website http://www.osti.gov/contact.html

This report was prepared as an account of work sponsored by an
agency of the United States Government. Neither the United States
Government nor any agency thereof, nor any of their employees,
makes any warranty, express or implied, or assumes any legal liability
or responsibility for the accuracy, completeness, or usefulness of any
information, apparatus, product, or process disclosed, or represents
that its use would not infringe privately owned rights. Reference herein
to any specific commercial product, process, or service by trade name,
trademark, manufacturer, or otherwise, does not necessarily constitute
or imply its endorsement, recommendation, or favoring by the United
States Government or any agency thereof. The views and opinions of
authors expressed herein do not necessarily state or reflect those of
the United States Government or any agency thereof.


ORNL/TM-2017/13

Computational Science and Engineering Division

\title{
ASSESSING THE COSTS AND BENEFITS OF INVESTMENTS IN CLIMATE RESILIENCE:
}

\section{TENNESSEE VALLEY AUTHORITY CASE STUDY}

\author{
Melissa Allen \\ Thomas J. Wilbanks \\ Benjamin L. Preston \\ Shih-Chieh Kao \\ James Bradbury \\ Prepared for the Office of Energy Policy and Systems Analysis, \\ US Department of Energy by Oak Ridge National Laboratory
}

January 2017

This document was prepared for the Department of Energy's Office of Energy Policy and Systems Analysis (EPSA). The Authors would like to thank the Tennessee Valley Authority for its assistance in the preparation of this document, as well as EPSA's Judi Greenwald and Sam Bockenhauer for their intellectual contributions and support. This research used resources of the Oak Ridge Leadership Computing Facility at the Oak Ridge National Laboratory, which is supported by the Office of Science of the US Department of Energy under Contract No. DE-AC05-00OR22725.

Prepared by

OAK RIDGE NATIONAL LABORATORY

Oak Ridge, TN 37831-6283

managed by

UT-BATTELLE, LLC

for the

US DEPARTMENT OF ENERGY

under contract DE-AC05-00OR22725 



\section{CONTENTS}

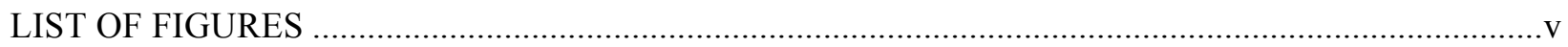

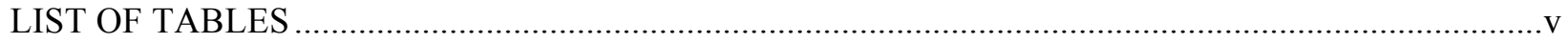

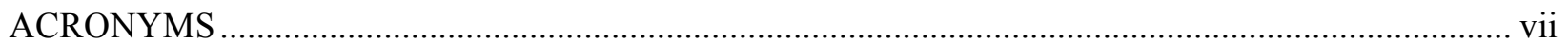

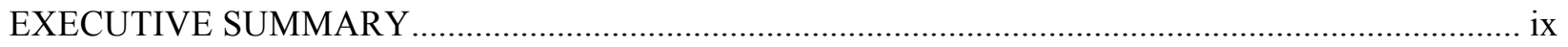

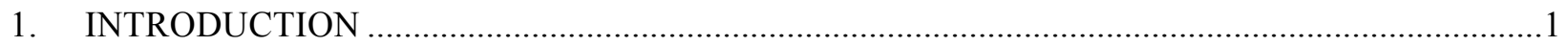

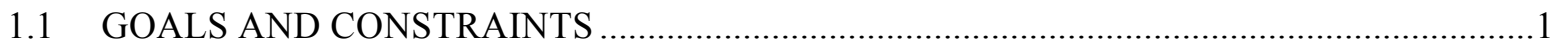

2. IDENTIFICATION OF INFRASTRUCTURES VULNERABLE TO THREATS ............................2

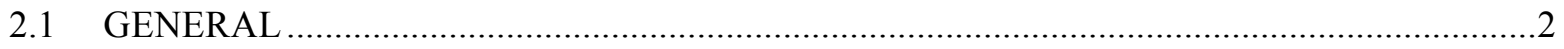

2.2 CLIMATE CHANGE AND EXTREME EVENTS SCENARIOS ….....................................

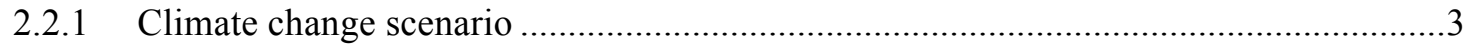

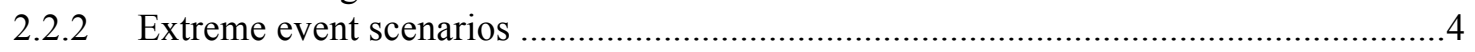

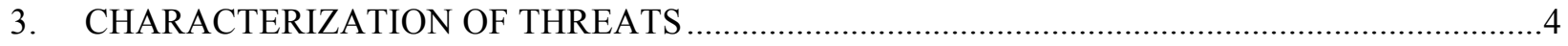

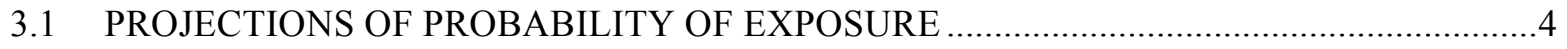

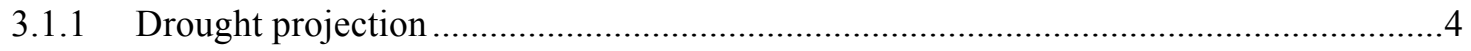

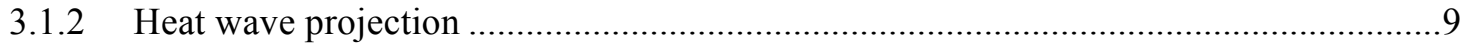

3.1.3 Sensitivities of electricity demand and supply...................................................

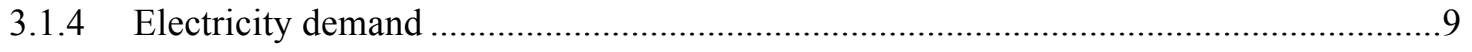

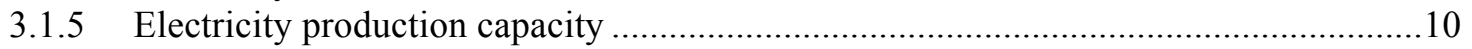

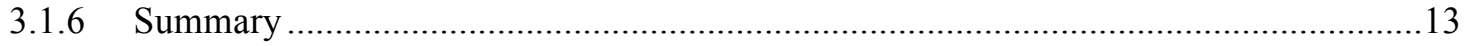

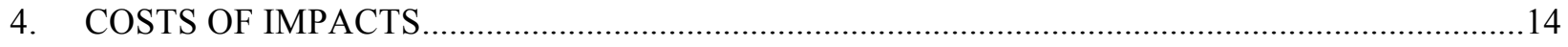

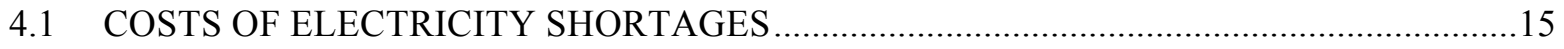

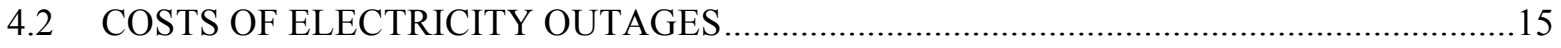

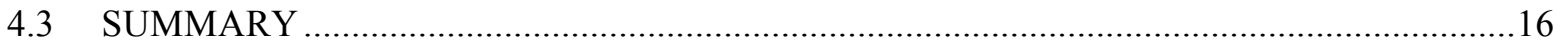

5. MODELING CLIMATE CHANGE COSTS-A CASE STUDY FOCUSED ON TVA

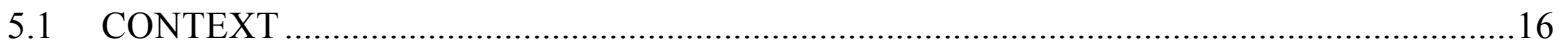

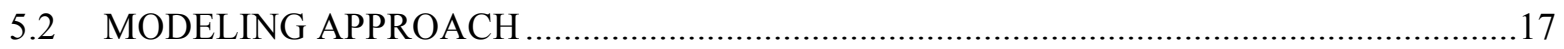

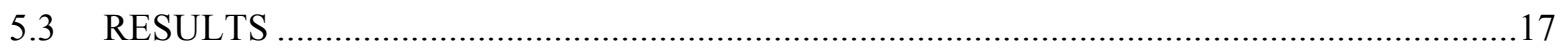

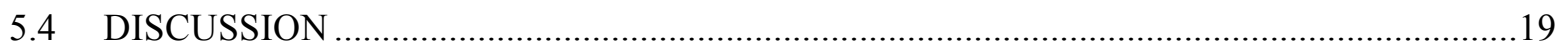

6. ADAPTATION SOLUTIONS FOR RESILIENCE ............................................................20

6.1 Enhanced efficiency (EE) in electricity use and system operation ......................................20

6.2 Changes in thermal electric power plant cooling approaches.................................................20

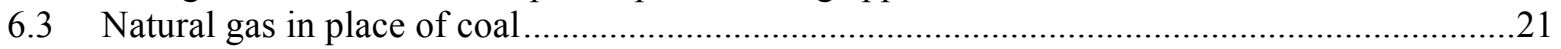

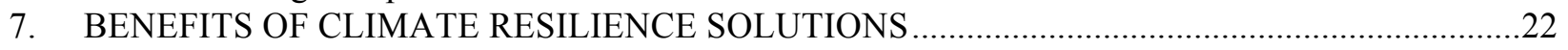

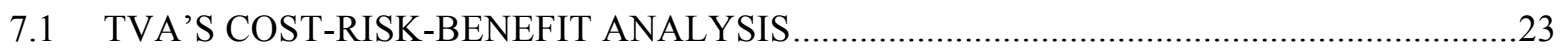

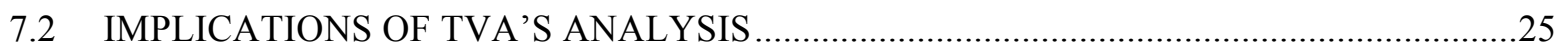

7.3 COSTS AND RESILIENCE BENEFITS OF ADAPTATIONS IN THE

CUMBERLAND RIVER BASIN AREA RELATED TO FUTURE THREATS.......................25

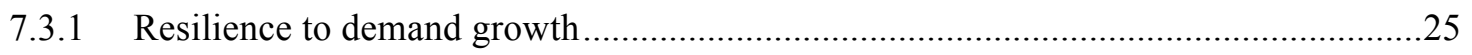

7.3.2 Resilience to warming surface water sources for cooling .......................................25

7.4 SUMMARY OF THE COST-BENEFIT ANALYSIS EXPERIENCE …..............................25

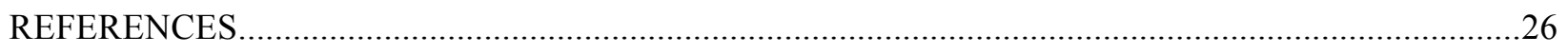

APPENDIX A. CALCULATION OF INCREASE IN ELECTRICITY DEMAND DUE TO

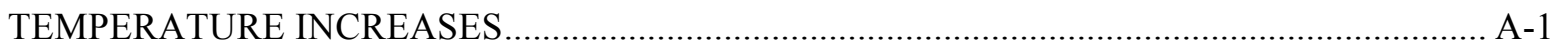

APPENDIX B. SCENARIOS, ASSUMPTIONS AND RESULTS OF THE STUDY .............................

APPENDIX C. METHODS FOR BAYESIAN MODELING OF HYDROPOWER SENSITIVITY

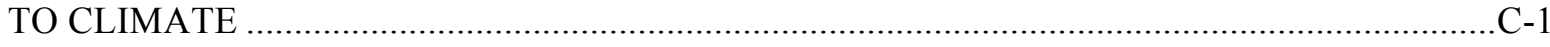





\section{LIST OF FIGURES}

Figure 1. Cumberland River electricity-generating plants and substations. ............................................2

Figure 2. Tennessee Valley Authority (TVA) customer service districts................................................

Figure 3. Standardized Precipitation Index (SPI) calculations for August 2007 using National

Centers for Environmental Prediction (NCEP) precipitation values.

Figure 4. Standardized Precipitation Index calculations for 2059 using dynamically downscaled

Community Earth System Model (CESM) values...................................................................... 6

Figure 5. Lake evaporation calculated from average monthly temperature for August 2055 ....................7

Figure 6. Stream temperature calculated from average monthly air temperature for August 2055.............8

Figure 7. Electricity consumption by county for Tennessee and Kentucky. ............................................9

Figure 8. Observed and modeled mean daily maximum temperature for Knox County, Tennessee, under RCP 8.5.

Figure 9. Observed and modeled days with maximum temperature above $95^{\circ} \mathrm{F}$ for Knox County, Tennessee, under RCP 8.5.

Figure 10. Estimates of (A) annual and (B) summer absolute generation anomalies based on historical conditions (observed and modeled) and a climate change scenario $(-20 \%$ rainfall and $2^{\circ} \mathrm{C}$ increase).

Figure 11. Estimates of the (A) annual and (B) summer economic value of summer generation anomalies based on historical conditions (observed and modeled) and a climate change scenario $\left(-20 \%\right.$ rainfall and $2{ }^{\circ} \mathrm{C}$ increase).

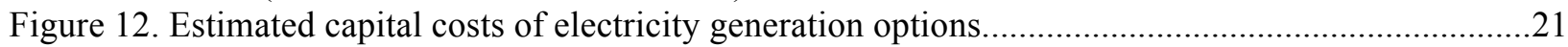

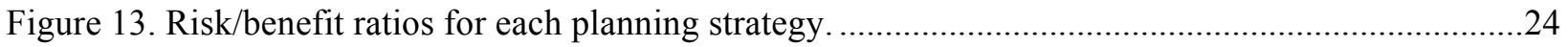

\section{LIST OF TABLES}

Table 1. Changes in total annual consumption with and without heat wave ............................................10

Table 2. Cumberland Valley types and capacities of electricity supply ..............................................10

Table 3. Effects of the climate change scenario on electricity production ..............................................12

Table 4. Cost of restoring normal power generation levels under current conditions ...............................15

Table 5. Tennessee Valley Authority planning strategies and their key characteristics (TVA 2015) .........23

Table 6. Tennessee Valley Authority planning scenarios and their key characteristics ............................24 


\section{ACRONYMS}

$\begin{array}{ll}\text { BBN } & \begin{array}{l}\text { Bayesian belief network } \\ \text { combined cycle }\end{array} \\ \text { CESM } & \text { Community Earth System Model } \\ \text { CIDM } & \text { Connected Infrastructure Dynamics Modeling } \\ \text { CMIP5 } & \text { Coupled Model Intercomparison Project, Version 5 } \\ \text { CT-only } & \text { combustion turbine only } \\ \text { DHS } & \text { Department of Homeland Security } \\ \text { DOE } & \text { Department of Energy } \\ \text { EE } & \text { enhanced efficiency } \\ \text { EIA } & \text { Energy Information Administration } \\ \text { EPA } & \text { Environmental Protection Agency } \\ \text { HUC } & \text { Hydrologic Unit Code } \\ \text { IRP } & \text { Integrated Resource Plan } \\ \text { NCEP } & \text { National Centers for Environmental Prediction } \\ \text { NGCC } & \text { natural gas combined cycle } \\ \text { NOAA } & \text { National Oceanic and Atmospheric Administration } \\ \text { OTC } & \text { once-through-cooling } \\ \text { RCP } & \text { Representative Concentration Pathway } \\ \text { SPI } & \text { Standardized Precipitation Index } \\ \text { TVA } & \text { Tennessee Valley Authority } \\ \text { WRF } & \text { weather research and forecasting }\end{array}$




\section{EXECUTIVE SUMMARY}

This report describes a general approach for assessing climate change vulnerabilities of an electricity system and evaluating the costs and benefits of certain investments that would increase system resilience. It uses Tennessee Valley Authority (TVA) as a case study, concentrating on the Cumberland River basin area on the northern side of the TVA region. In particular, this study focuses on evaluating the risks associated with extreme heat wave and drought conditions that are projected to affect the region by midcentury. Extreme climate event scenarios were developed using a combination of dynamically downscaled output from the Community Earth System Model and historical heat wave and drought data from 1993 and 2007, respectively.

Under such conditions, the efficiency of fossil fired generation units would be reduced. Higher air temperatures reduce gas turbine efficiency, and less availability of cooling water and higher intake water temperatures reduce cooling efficiency. Hydroelectric power generation would be reduced as a result of decreased water flow from drought conditions, and increased evaporation from extreme heat. Overall, the impact is expected to cause a reduction in generation capacity, and losses of generation efficiency at the same time that cooling degree days increase and therefore electricity demand for cooling is higher. Simultaneous shortfalls in generation and increases in demand for electricity is assumed to require purchases of power from the wholesale market with a total net cost of roughly half a million dollars per day.

Additionally, Bayesian modeling was conducted to estimate hydropower anomalies based on streamflow and temperature data. Streamflow anomalies associated with specific hydropower facilities are found to be a robust predictor of monthly and annual generation anomalies. The model was then used to estimate future costs associated with projected changes in climate, finding that losses are anticipated to occur on both an annual and seasonal basis relative to historical conditions. Over the course of an entire year, estimated impacts to hydroelectric power generation alone range from $\$ 80 \mathrm{M}$ to $\$ 153 \mathrm{M}$ in lost revenue.

The costs of climate change impacts can be reduced by adaptation strategies and actions that add resilience to the electricity system. In general, adaptation options include several categories, all of which are considered in TVA's 2015 Integrated Resource Plan (IRP). In particular, TVA considered several adaptation options, including 1) enhancing the energy efficiency of electricity use and system operations, 2) changing approaches to thermal electric power plant cooling, 3) building natural gas capacity in place of coal, 4) increasing use of renewable energy resources that are not water-consumptive during operation, 5) increasing energy storage, and 6) expanding long-distance interconnections.

This report found that cost-benefit analysis, combined with risk assessment, is a useful tool to explore strategies for resilience enhancement of electricity systems facing known future threats and challenges. This method is generally most useful for estimating the value of resilience investments in the relatively near future, such as the 20-year time horizon used in TVA's IRP. Cost-benefit analysis of longer-term resilience options is more challenging but remains a useful tool to enable decision-making strategies that minimize risk and favor investments with multiple co-benefits. 



\section{INTRODUCTION}

The first installment of the Quadrennial Energy Review (QER) recommended the Department of Energy (DOE) collaborate with the Department of Homeland Security (DHS) and stakeholders to "develop comprehensive data, metrics, and an analytical framework for energy infrastructure resilience, reliability, and asset security" (DOE, 2015). This recommendation complements related efforts underway in collaboration with electric utility companies through the Partnership for Energy Sector Climate Resilience. These new initiatives create opportunities for DOE and utility partners to collaboratively develop and deploy tools for assessing climate change vulnerabilities, and to assist in evaluating the costs and benefits of climate resilience investments. This report outlines a general approach and initial demonstration, using the Tennessee Valley Authority (TVA) region as a case study.

TVA is a US federal corporate agency that provides electricity to businesses and local power distributors that serve 9 million people across seven southeastern states. The majority of TVA's power is produced from coal and nuclear reactors, $40 \%$ and $33 \%$ respectively. The remainder is produced from natural gas $(13 \%)$, hydroelectric generators $(10 \%)$, and renewables $(3 \%)$. TVA has produced a number of reports that are valuable source materials. ${ }^{1}$ In 2014, TVA released its Climate Change Adaptation Plan as a cohesive part of its planning initiatives, including integrated resource management, natural resource, and National Environmental Policy Act (NEPA) planning processes. The Climate Change Adaptation Plan identifies climate risks that could impede TVA's ability to perform its overall mission and possible adaptation strategies. In 2015, TVA published its Integrated Resource Plan (IRP), which will guide decision-making about how to meet future electricity demand through the year 2033 (TVA, 2015). The IRP, developed with in-depth analysis and public feedback, acknowledges the current plans for coal plant retirements and emphasizes the increased use of natural gas, demand response, energy efficiency, and renewables.

The TVA's general approach includes the following components:

1. Goals and constraints

2. Vulnerability of infrastructure to climate change threats

3. Characterization of threats

4. Costs of climate change impacts

5. Costs of climate resilience solutions to impact vulnerabilities

6. Benefits of climate resilience solutions

\subsection{GOALS AND CONSTRAINTS}

The goal of this analysis is to develop a general approach for assessing the climate change vulnerabilities of an electricity system and to evaluate the costs and benefits of climate resilience investments. It combines resources from Oak Ridge National Laboratory (ORNL) and ORNL's neighbor, TVA, to provide results from a case study, concentrating on the Cumberland River basin area on the northern side of TVA's service region at TVA's request.

This analysis was conducted with a number of constraints, none of which significantly reduced the value of the study as a demonstration of a general approach

- Most of the data used for this analysis were drawn from publicly available sources.

\footnotetext{
${ }^{1}$ For example, TVA (2014). Climate Change Adaptation Plan; EPRI (2009), Potential Impact of Climate Change on Natural Resources in the Tennessee Valley Authority Region; TVA (2015). Integrated Resource Plan.
} 
- As the basis for a preliminary assessment of possible impacts and in the absence of projections of TVA infrastructure for 2050-2059, the analysis assumed current facilities are unchanged between now and 2050.

- Because of resource limitations, it was agreed ORNL would develop order-of-magnitude cost estimates for climate change impacts, as well as estimate adaptation costs and benefits.

- TVA's request to limit this analysis to the Cumberland River basin area introduced an institutional complication: the dams and hydropower on that river are owned by the US Army Corps of Engineers rather than TVA.

\section{IDENTIFICATION OF INFRASTRUCTURES VULNERABLE TO THREATS}

\subsection{GENERAL}

At TVA's request, this analysis of vulnerabilities, impacts, and possible adaptive responses was limited to the Cumberland River drainage basin portion of the TVA region. Figure 1 identifies the electricity production and distribution facilities in this region, according to ORNL's data resources supporting its Connected Infrastructure Dynamics Modeling (CIDM) program, drawn primarily from HSIP Gold/HSIP Freedom. Figure 1 also shows the electricity generation facilities, which include thermal, hydro, and "other." Figure 2 shows the TVA distributors in the area.

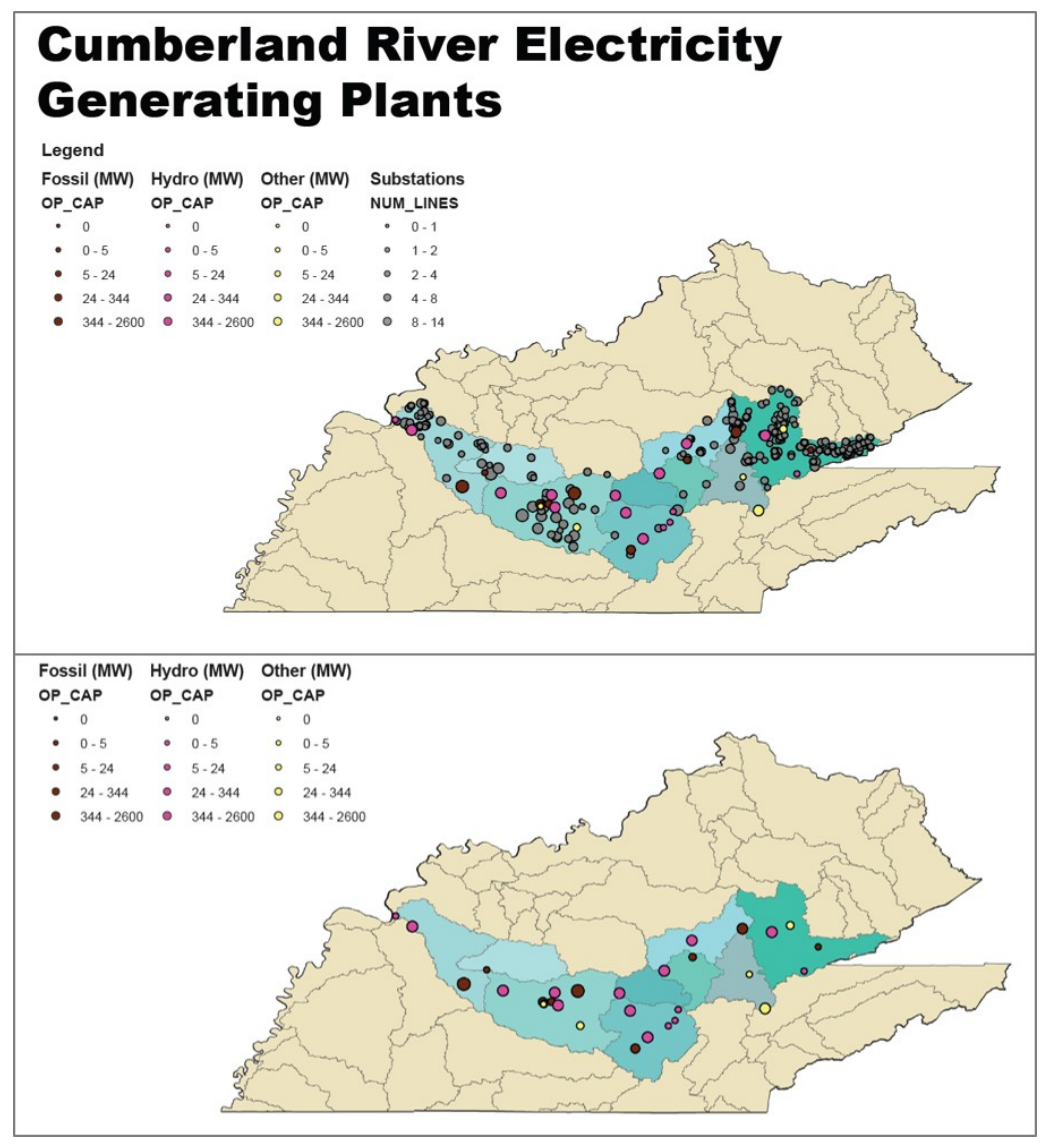

Figure 1. Cumberland River electricity generating plants and substations. The operational generating capacity for each fuel type is given in megawatts. 


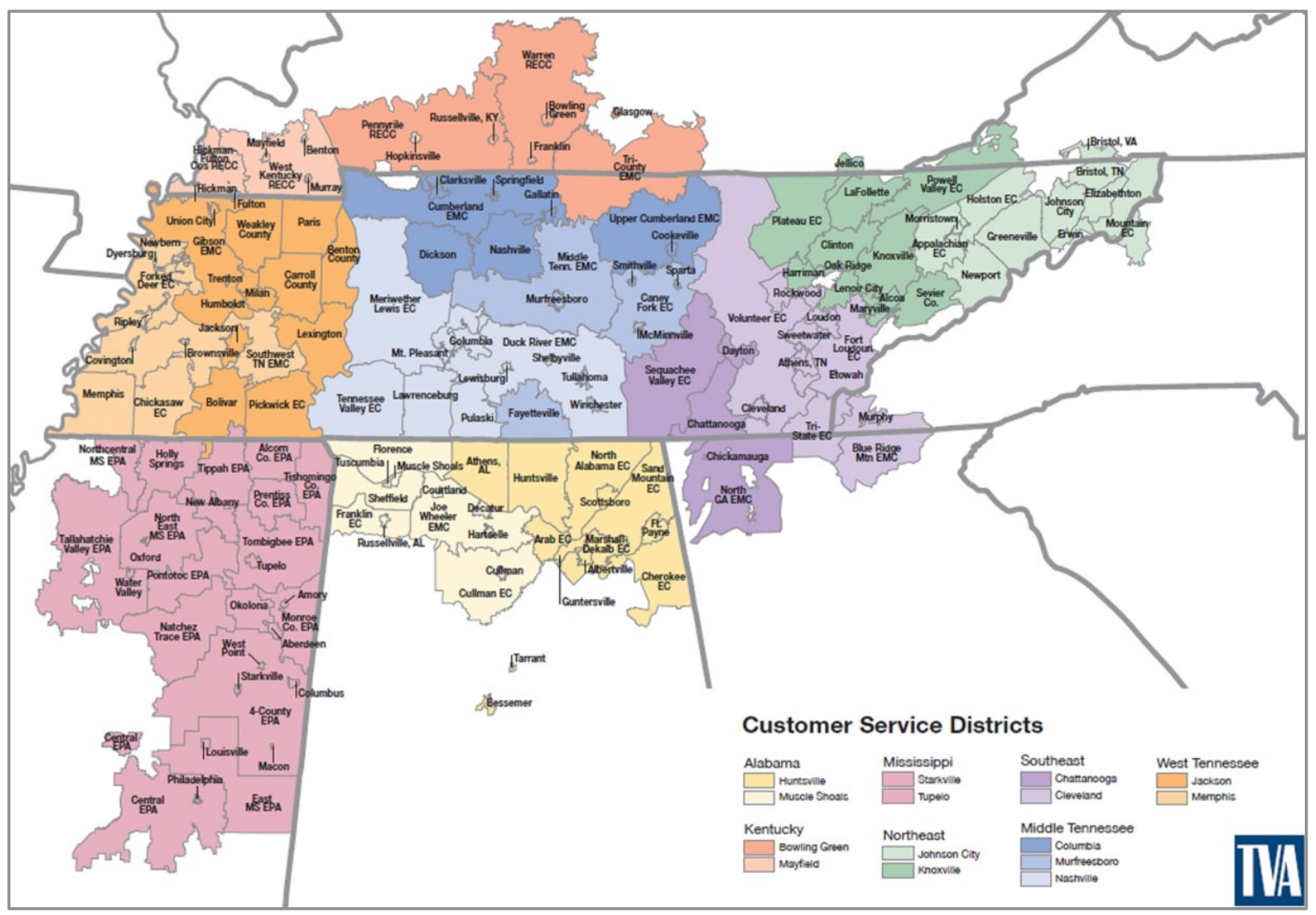

Figure 2. Tennessee Valley Authority (TVA) customer service districts.

At the outset of the project, DOE, TVA, and ORNL collaboratively decided to focus this case study on the combined effects of a combination of a severe summer drought in the 2050s and a severe summer heat wave in that same period., in order to evaluate impacts and costs of the events on electricity services in the area and to serve as a backdrop for considering costs and benefits of adaptation options to add resilience. Historical analogues of major regional droughts and heat waves in the recent past were used to provide perspectives on the magnitude and duration of such events. In particular, the drought of 2007 and the summer heat wave in 1993 were selected as particularly salient in the region (Sections 2-3 and Appendices A-C).

\subsection{CLIMATE CHANGE AND EXTREME EVENTS SCENARIOS}

\subsubsection{Climate change scenario}

Dynamically downscaled historical and Representative Concentration Pathway (RCP) scenarios (RCP 8.5) using initial and boundary conditions generated by the Coupled Model Intercomparison Project, Version 5 (CMIP5) ensemble member, Community Earth System Model (CESM), at three hour intervals for Weather Research and Forecasting (WRF) domain simulations at $4 \mathrm{~km}$ resolution (Gao et al., 2012) were selected for the study. RCP 8.5 is one of four RCPs, and it is the highest greenhouse gas concentration scenario. Consequently, it has come to be used in US climate change science as a representation of a climate future in which there is only limited global success mitigating emissions. This $\mathrm{RCP}$ was selected to illustrate a worst-case scenario future. 


\subsubsection{Extreme event scenarios}

\subsubsection{Heat waves}

RCP 8.5 shows considerable warming by 2050 , enough that typical summer high and low temperatures over a period of weeks or months might have been called a heat wave half a century before. But a heat wave is defined by unusually warm days and nights compared with typical temperatures. The 1993 heat wave (Lott, 1994), compared with typical summer high and low temperatures at that time in 1993, provides a quantitative basis for adding temperature increments to the typical temperatures in 2050 to simulate a future heat wave in that period, based on estimated temperature anomaly data for small geographic units. During the 1993 heat wave in the southeastern United States, daily maximum temperatures were $4 \%-7 \%$ above the 30 -year historical average daily maxima. For this study, these percentages are applied to the already elevated temperatures of the projected 2050s July maxima.

\subsubsection{Standardized Precipitation Index (SPI) for drought}

Because of deficiencies in cloud parameterization and other important subgrid processes, climate models lack the capability to predict extreme precipitation events such as floods and drought (Randall et al., 2003). Thus, the model output alone for future climate simulations such as RCP 8.5 cannot show potential drought conditions for the 2050s. Therefore, to simulate future drought, dry conditions must be inserted into the modeling framework. In this case, a possible future drought scenario is developed based on observational data for the 2007 Southeast drought (Seager et al., 2009). This is methodologically complex because drought is a cumulative phenomenon. However, the Standardized Precipitation Index (SPI) provides a way to represent drought as a cumulative distribution function at a monthly time scale based on historical data (McKee et al., 1993). Thus, an analyst can use historical data to determine the probability of rainfall being less than or equal to a given (i.e., normal) amount.

For this study, the 2050 impacts on water supply were developed by comparing cumulative precipitation data for the 2007 drought and water availability data in that period. Water availability in 2050 is further reduced by increased evaporation resulting from higher temperatures. Assuming a 2050 drought worse than 2007 because of higher evaporation and possible longer duration, this study used the 2007 relationship between lack of precipitation and water scarcity as a basis for incremental adjustments in water availability estimates for 2050 .

\section{CHARACTERIZATION OF THREATS}

Characterizing climate-related threats to TVA's electricity systems in the Cumberland River subregion included two kinds of analysis:

1. Projections of the probability of exposure to unusual climate-related conditions. For this case study, a severe drought and heat wave in the 2050-2059 period was used.

2. Sensitivities of electricity supply and demand systems to those exposures.

\subsection{PROJECTIONS OF PROBABILITY OF EXPOSURE}

\subsubsection{Drought projection}

To simulate drought conditions for 2050 or adjacent years, the 2007 drought at its most severe was defined using the National Centers for Environmental Prediction (NCEP) reanalysis data by computing 12 month and 24 month Standardized Precipitation Indices (SPI) for each grid cell through August, 2007 
(Figure 3, Figure 4). Because this method does not take evapotranspiration into account, we calculated additional lake evaporation using the National Oceanic and Atmospheric Administration (NOAA) empirical formula developed by Grunsky (1932). The calculation of daily lake evaporation is based on air temperature alone (no wind) and the following equation:

$$
E^{\prime}=0.0022 e^{0.0557 T}
$$

where $E^{\prime}$ is the lake evaporation in inches per day, and $T$ is the air temperature in degrees Fahrenheit. Monthly evaporation is summed over the number of days in August. This quantity is then subtracted from the monthly precipitation input to the SPI calculation to arrive at a reduced amount of water available in the lakes during the drought period.

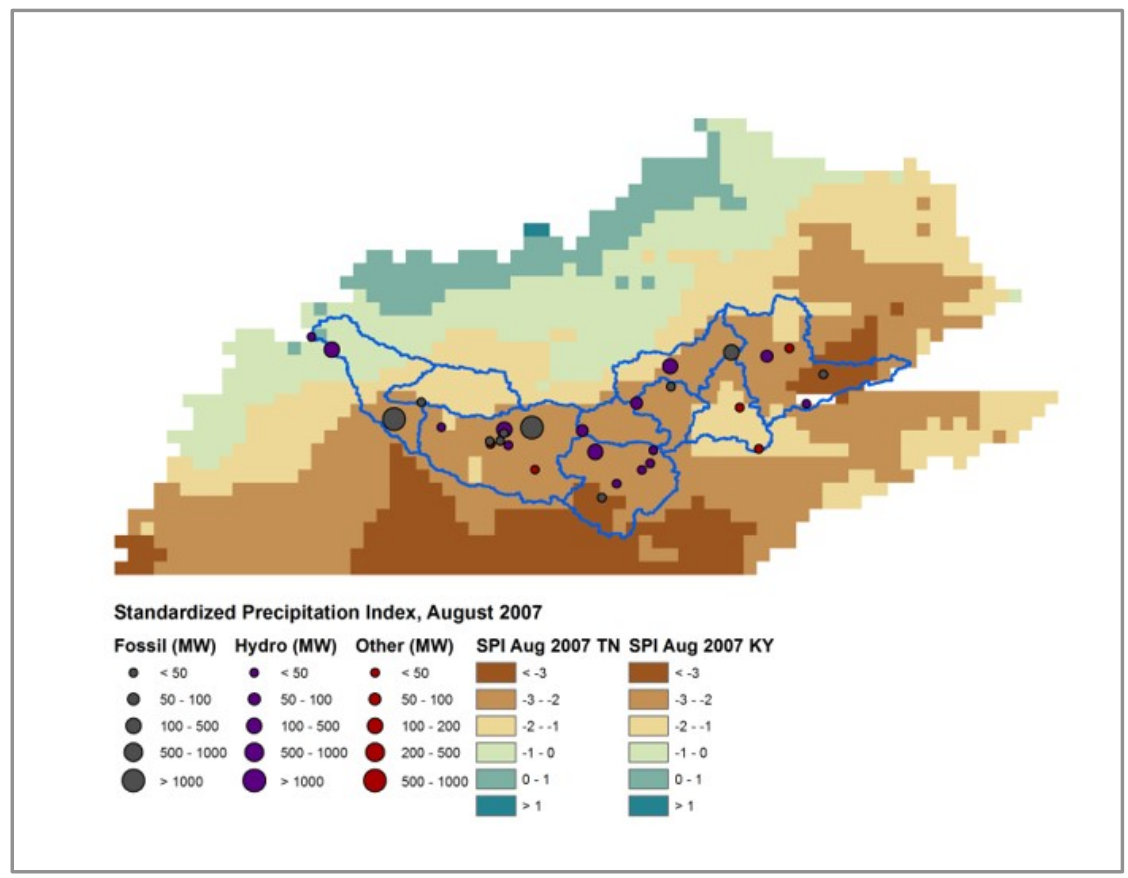

Figure 3. Standardized Precipitation Index (SPI) calculations for August 2007 using National Centers for Environmental Prediction (NCEP) precipitation values. Generation capacities for each fuel type are given in megawatts. SPI values are explained in Section 3.1. 


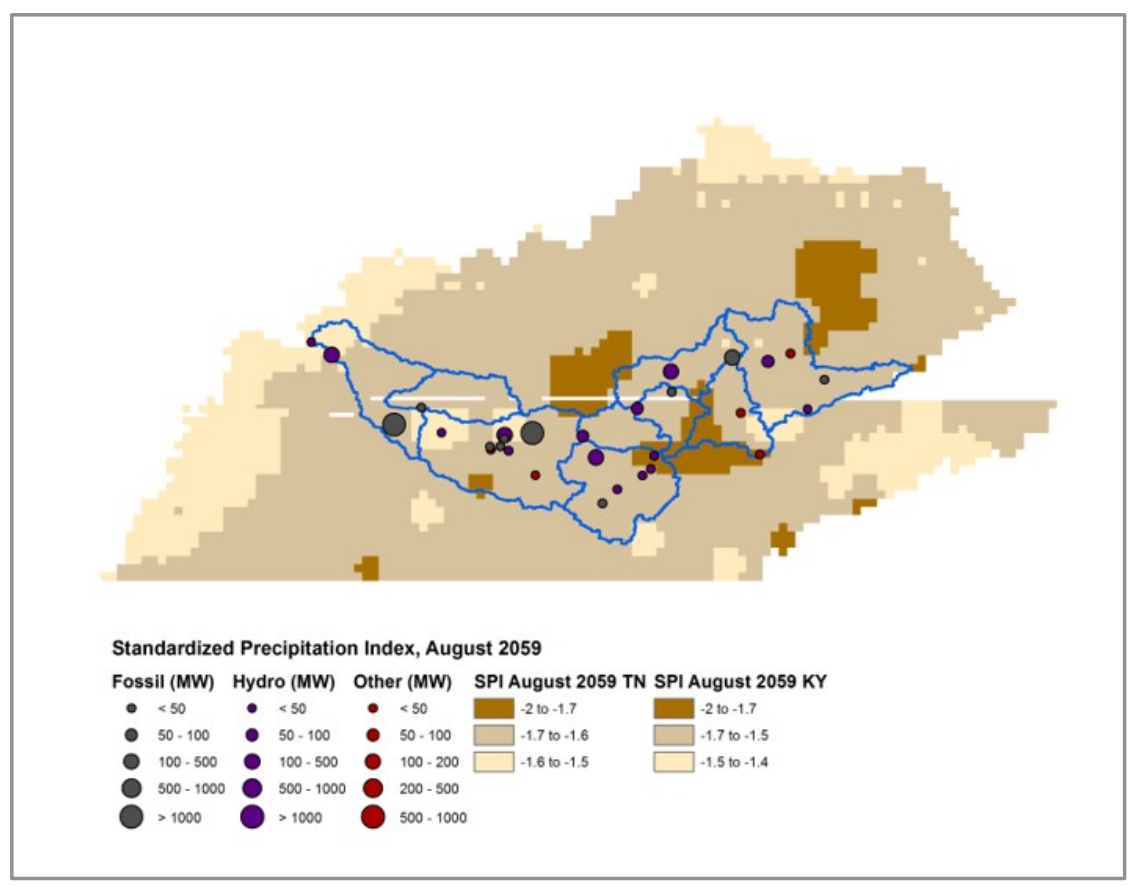

Figure 4. Standardized Precipitation Index calculations for 2059 using dynamically downscaled Community Earth System Model (CESM) values. In both states, every location in both states is $1-2$ standard deviations drier than normal for that year. Compared with the 2007 drought, this amounts to wetter conditions for southern Tennessee and drier conditions for northern Kentucky. Generation capacities for each fuel type are given in megawatts.

This hybrid SPI calculation was used to determine 2007 drought conditions and potential 2059 drought conditions. For 2007, lake evaporation resulting from average temperatures associated with the 2007 drought was calculated (Figure 5) using the Grunsky formula. For 2059, lake evaporation resulting from projected average temperatures for 2059 was similarly estimated (Figure 6). In each case, 5 years of average monthly precipitation data before the August of the most extreme part of the drought are taken from NCEP (2007) and the downscaled CESM data (2059). These data sources provide the sample size for the SPI calculation input for each respective period. 


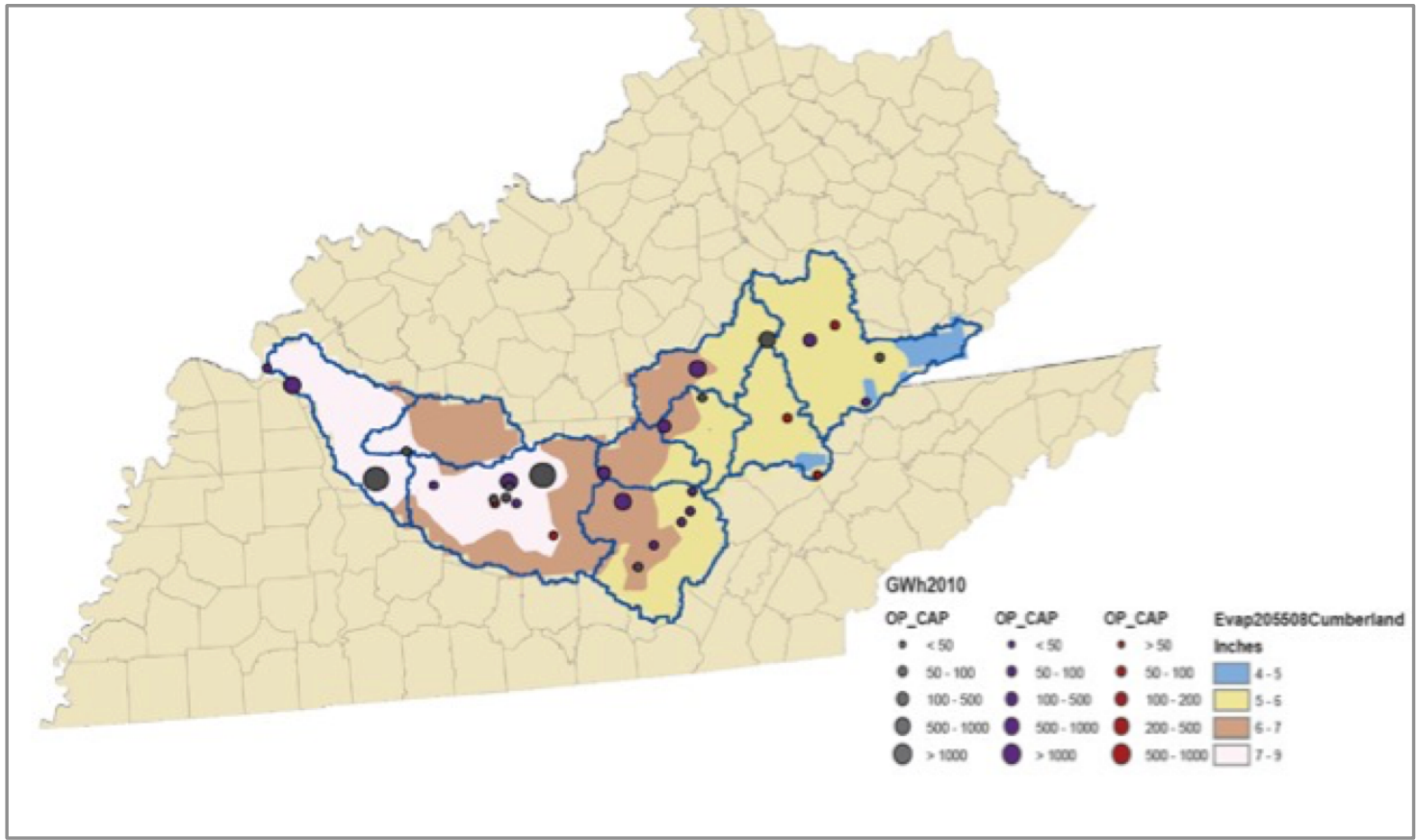

Figure 5. Lake evaporation calculated from average monthly temperature for August 2055. Data are from the downscaled Community Earth System Model (CESM) Coupled Model Intercomparison Project, Version 5 (CMIP5) projections. Generation capacities for each fuel type are given in megawatts. 


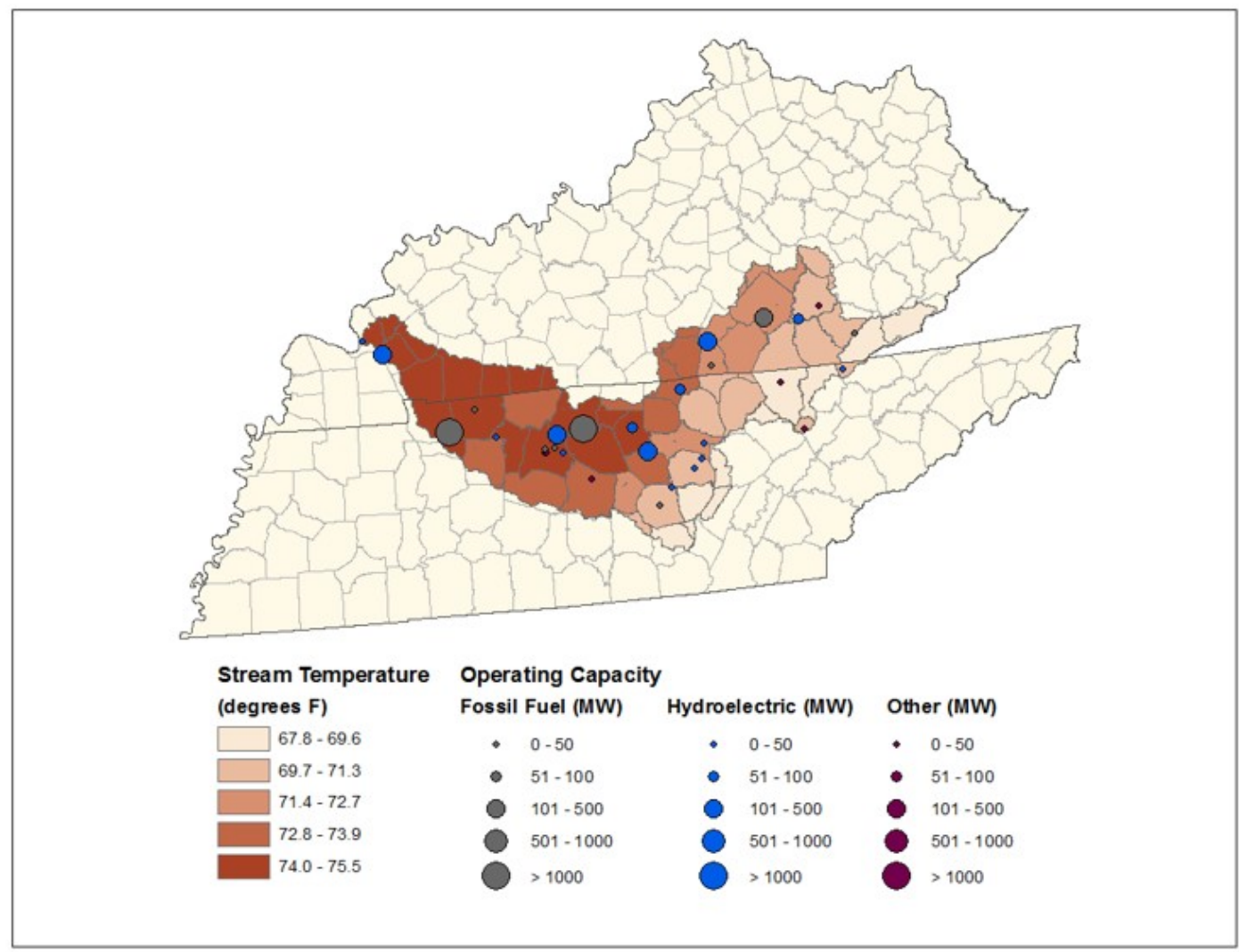

Figure 6. Stream temperature calculated from average monthly air temperature for August 2055. Data are from the downscaled Community Earth System Model (CESM) Coupled Model Intercomparison Project, Version 5 (CMIP5) projections. Generation capacities for each fuel type are given in megawatts.

SPI values indicate that -1.0 to -1.5 is "moderately dry," -1.5 to -2.0 is "severely dry," and -2.0 or less is "extremely dry." The values are based on streamflows and reservoir levels and, for longer time scales, groundwater levels. The main difference between the drought conditions in 2007 and those simulated for 2059 is that the 2007 drought had localized areas of greater severity than those projected for the 2059 drought, but the 2059 drought is more widespread.

Monthly average stream temperature (Figure 6) is calculated using the linear relationship between air temperature and stream temperature formulated by Morrill et al. (2005):

$$
T_{s}=A T_{a}+B
$$

$T_{a}$ is the measured dry air temperature, and $T_{s}$ is the stream temperature. The slope, $A$, is taken from Table 2 in Morrill et al. and is the "All" value (0.71), which represents the slope averaged across all measured streams of varying altitude. The y-intercept, $B$, is the "All" value (2.56) from the same table.

Calculated monthly lake evaporation values for each Hydrologic Unit Code (HUC) region in August 2055 not experiencing the heat wave are an average of $173 \%$ higher than the 2007 rate because of the higher temperatures in 2055 under RCP 8.5 (Figure 5) The lake evaporation projection and the projection of very high stream temperatures are caused by high ambient air temperatures. Clearly, the scenario indicates very dry, hot conditions. If $T a$ is increased by $6 \%-7 \%$ (Fahrenheit scale), additional evaporation resulting from the heat wave can be calculated as well, as was done in the hybrid SPI calculation. 


\subsubsection{Heat wave projection}

A severe heat wave in the 2055-2059 period was simulated using observational data for the 1993 Southeast heat wave superimposed on the RCP 8.5 climate change scenario. That is, the magnitude of the 1993 heat wave in the Cumberland River basin registered daily temperatures $6 \%-7 \%$ above normal for a duration of 17-30 days. Meehl and Tebaldi's (2004) metrics for calculating heat waves were used. The projected peak of the heatwave is a 3 day minimum temperature of $72^{\circ} \mathrm{F}-82^{\circ} \mathrm{F}$ and a 3 day maximum temperature of $100^{\circ} \mathrm{F}-105^{\circ} \mathrm{F}$. Anomalies were calculated by taking the daily maximum temperature from 1993 and subtracting the average daily maximum temperature and finding the percentage difference.

\subsubsection{Sensitivities of electricity demand and supply}

A preliminary assessment of implications of these climate conditions for the electricity system was conducted assuming that the 2050 Cumberland River electricity infrastructure is the same as at present.

\subsubsection{Electricity demand}

Population increase to the 2050s is determined using the LandCast (McKee et al., 2015) method, which assumes urban development will follow population changes determined using the US Census cohort component and urbanization projections. Table 1 shows electricity consumption for counties in the Cumberland River basin area (Figure 7). In 2010, the total annual consumption was 53,919 GWh. Projected consumption in 2050, reflecting population growth and temperature increase from climate change (calculation given in Appendix A) but no heat wave, is 81,991 $\mathrm{GWh}$. With the heat wave added, the projected consumption rate is $14 \%$ higher, and total consumption is $73 \%$ higher for the period of the heat wave than in 2010 (Table 1).

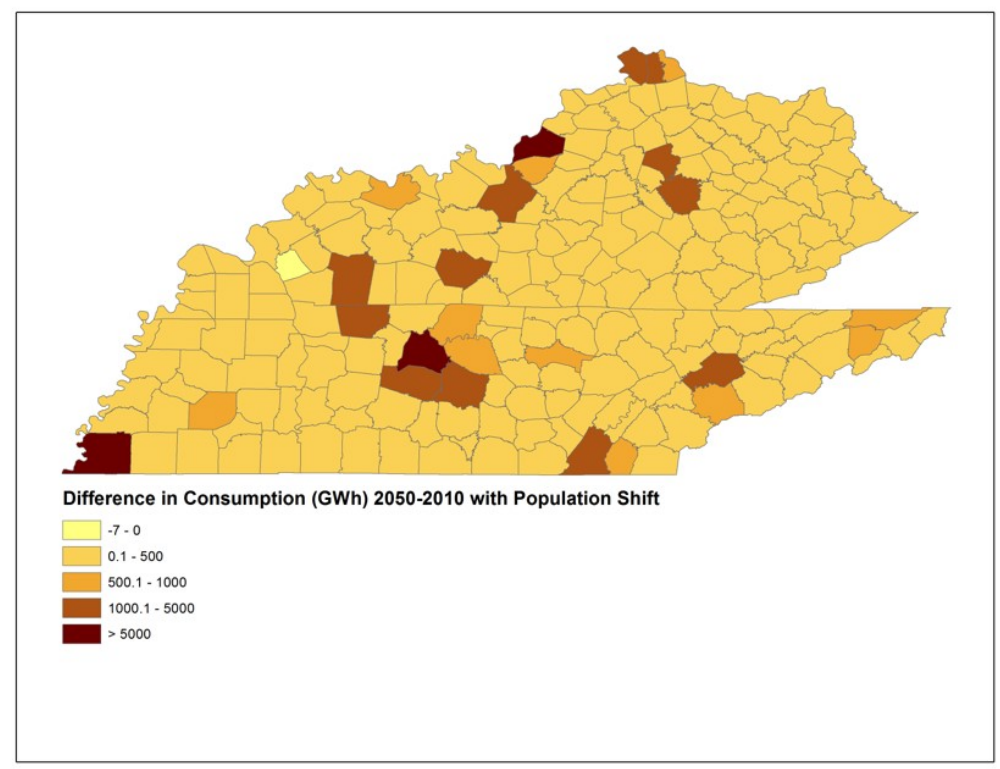

Figure 7. Electricity consumption by county for Tennessee and Kentucky. This is calculated by taking the Energy Information Administration (EIA) consumption values for each state and disaggregating it based on county population usage at the average per capita state rate. The 2050 calculations assume the 2010 average per capita consumption in each state is the same in 2050. Increases in county consumption are caused by increases in population alone. 
Table 1. Changes in total annual consumption with and without heat wave

\begin{tabular}{|c|c|c|c|}
\hline Year & Total annual consumption & Condition & Change \\
\hline 2010 & $53,919 \mathrm{GWh}$ & Historical data & $\mathrm{N} / \mathrm{A}$ \\
\hline 2050 & $81,991 \mathrm{GWh}$ & $\begin{array}{l}\text { RCP } 8.5 \text { warming, no heat } \\
\text { wave }\end{array}$ & $52 \%$ above 2010 \\
\hline 2050 & $93,470 \mathrm{GWh}$ & $\begin{array}{l}\text { RCP } 8.5 \text { warming, plus } \\
\text { heat wave }\end{array}$ & $73 \%$ above 2010 \\
\hline
\end{tabular}

\subsubsection{Electricity production capacity}

Electricity production capacity in the Cumberland River basin is based on hydropower, fossil-based thermal power generation, and other renewable energy sources (Table 2). Current capacity in these categories is 4,200 MW for fossil and $914 \mathrm{MW}$ for hydropower. The capacity of the "other" source category - which includes black liquor waste products, photovoltaics, and wind power - is about $270 \mathrm{MW}$, plus $857 \mathrm{MW}$ for the Raccoon Mountain pumped storage plant. Note the dominance of thermal power in the regional mix.

Table 2. Cumberland Valley types and capacities of electricity supply

\begin{tabular}{|l|c|}
\multicolumn{1}{|c|}{ Generation Source } & Capacity \\
\hline Fossil & $4,200 \mathrm{MW}$ \\
\hline Hydro & $914 \mathrm{MW}$ \\
\hline Other & $270 \mathrm{MW}$ \\
\hline Pumped storage & $857 \mathrm{MW}$ \\
\hline
\end{tabular}

\subsubsection{Hydropower}

The drought and heat wave would affect hydropower production in three ways:

1. It would reduce precipitation and water flow in the drainage basin.

2. It would increase evaporation rates from surface water bodies, reducing water volume.

3. It would increase competing demands for cooler upstream water to be moved downstream for power plant cooling and for periodic maintenance of dissolved oxygen levels for biota, regardless of the implications for hydropower production.

The actual impact of these effects would depend substantially on utility water management policies and practices. TVA is very experienced in dealing with fluctuations in precipitation and surface water availability and competing demands for hydropower, power plant cooling water, and other priorities to the valley's resource management. The 2007 drought offers an example. TVA statements at the time indicated that hydropower production for that year was only $68 \%$ of normal for the entire year. TVA sources reported that hydropower generation was reduced by $50 \%$ because of the drought.

The postulated 2050-2059 drought would be more widespread than the 2007 drought, so it is reasonable to estimate that hydropower production for that decade would be $35 \%-60 \%$ of normal rates, depending on TVA decisions about the allocation of scarce water for alternative uses. Production would fall in the lower part of that range during summer months, including the period of the heat wave. TVA uses the water in its reservoirs for a variety of purposes: hydropower generation, releasing cooler water from upstream to reduce temperatures in downstream waters used for cooling thermal power plants, navigation, 
and others. In recent decades, a majority of the total flow in the entire TVA region has been allocated to power plant cooling rather than hydropower generation; however, TVA has latitude to vary the proportions depending on priorities. ${ }^{2}$ Section 5 of this report includes a quantitative modeling exercise that estimates the implications of future drought and heat wave scenarios for hydropower generation.

\subsubsection{Fossil energy power generation}

ORNL research for DOE Office of Science's Regional Integrated Assessment Modeling project shows the drought and heat wave would affect thermal electricity production in four ways:

1. Higher ambient air temperatures would adversely affect gas turbine efficiency.

2. Surface water for power plant cooling would be less available.

3. Higher intake water temperatures would adversely affect power plant cooling efficiency.

4. Higher ambient water temperatures would increase the temperature in the "mixing zone" above Environmental Protection Agency- (EPA-)mandated temperature limits. The mixing zone temperature might be increased by warmer plant discharges, warmer ambient receiving waters, or both.

Water temperature is specifically regulated by Tennessee Cumberland Watershed Environmental Water Quality Rules:

The maximum water temperature change shall not exceed $3^{\circ} \mathrm{C}$ relative to an upstream control point. The temperature of the water shall not exceed $30.5^{\circ} \mathrm{C}$ and the maximum rate of change shall not exceed $2^{\circ} \mathrm{C}$ per hour. The temperature of impoundments where stratification occurs will be measured at a depth of 5 feet or mid-depth, whichever is less, and the temperature in flowing streams shall be measured at mid-depth.

Estimating the impacts of these factors on thermal electricity production for a drought beginning in 2050 would require a detailed plant-by-plant analysis to identify sensitivities to water temperature increases. Utilities have coping strategies that can be employed, such as shutting down some units but not others and modifying water intake pipes, and TVA can reduce intake water temperatures for downstream plants by releasing cooler water from upstream reservoirs. Nevertheless, in 2007 Duke Energy had to cut power generation at two coal-fired power plants because the temperatures of discharged water into "mixing zones" exceeded EPA limits. This reduced production caused a number of blackouts (Brashears, 2007).

Analyses conducted for DOE by ORNL and two other national laboratories showing the impacts of the same types of extreme events (overall temperature increase plus drought and heat wave) in the upper Midwest for the 2050-2059 period have indicated that 27\% of thermal energy production in the state of Illinois would be reduced (publication pending). They also show that the current mix of electricity generation facilities in a smaller part of the Chicago metropolitan area, if continued until a period with a drought and a heat wave in 2054 , would fall short of estimated electricity demand in that small area by $57.8 \%$, demonstrating the potential for blackouts unless a considerable amount of power could be purchased from the wholesale electricity market.

\footnotetext{
${ }^{2}$ Dams and hydropower facilities in the Cumberland River watershed are owned by the US Army Corps of Engineers, not by TVA, and the resulting electricity is owned by US the Army Corps of Engineers. TVA provides river scheduling services for the US Army Corps of Engineers. To demonstrate the methodology of this experiment, electricity system issues for the Cumberland River watershed were simulated as if TVA owned the dams and facilities, but the hydropower parts of the discussion should be understood as hypothetical simulations.
} 
Table 3. Effects of the climate change scenario on electricity production

\begin{tabular}{|c|c|c|c|}
\hline Type of evidence & Fossil energy & Hydropower & Total impacts \\
\hline $\begin{array}{l}\text { Qualitative } \\
\text { information on } \\
\text { generation impacts }\end{array}$ & $\begin{array}{l}\text { Affected by higher air } \\
\text { temperature effects on gas } \\
\text { turbine efficiency, } \\
\text { reductions in availability } \\
\text { of cooling water, higher } \\
\text { intake water temperatures } \\
\text { reducing cooling } \\
\text { efficiency, and possible } \\
\text { violations of EPA- } \\
\text { mandated "mixing zone" } \\
\text { temperature limits (case } \\
\text { specific). }\end{array}$ & $\begin{array}{l}\text { Affected by reduced } \\
\text { water flow, due to } \\
\text { drought, increased } \\
\text { evaporation, and } \\
\text { increased demands for } \\
\text { cooling. }\end{array}$ & $\begin{array}{l}\text { Results in reduction in } \\
\text { generation capacity as } \\
\text { well as losses of } \\
\text { generation efficiency }\end{array}$ \\
\hline $\begin{array}{l}\text { Quantitative } \\
\text { information on } \\
\text { generation impacts }\end{array}$ & $\begin{array}{l}\text { Estimated that downriver } \\
\text { large power plants would } \\
\text { be forced to shut down at } \\
\text { least one unit, with a net } \\
40 \% \text { reduction in summer } \\
\text { capacity, compared with } \\
\text { normal. }\end{array}$ & $\begin{array}{l}\text { Hydropower generation } \\
\text { estimated to be } 35 \%-60 \% \\
\text { of normal, depending on } \\
\text { TVA allocations for } \\
\text { alternative uses }\end{array}$ & $\begin{array}{l}\text { Results in potential loss of } \\
\text { up to } 2,300 \mathrm{MW} \text { of total } \\
\text { generation capacity for } \\
\text { the Cumberland River } \\
\text { basin }\end{array}$ \\
\hline
\end{tabular}

For the Cumberland River area, it is risky to draw firm conclusions about impacts for a larger region from such a small sample of fossil energy power plants (10), but it is clear that fossil electricity generation in the area would be vulnerable to impacts of a severe drought plus a heat wave. We focused on three large coal-fired plants that account for virtually all the available capacity in the study area: Cooper, Gallatin, and Cumberland. Based on the limited experiences of other utilities in the past (e.g., Brashears, 2007), several of the current larger power plants downstream would face challenges with source water temperature, and some might face pressures to reduce or temporarily stop operation. A worst-case analysis of three large plants indicates that the down-river Gallatin and Cumberland power plants could be forced to shut down at least one unit, and the up-river Cooper power plant might also be at risk of a reduction in power generation, while at the same time effects of higher operating temperatures on turbine efficiency would reduce available capacity in all three power plants. The overall effect could be a net reduction in available capacity from fossil fuel of more than 1,700 MW compared with nominal summer capacity (4,200 MW, as indicated in Tables 2 and 3), or 40\%. This does not consider possible further limitations from mixing zone regulations, which would appear to be likely given the drought scenario projection of very high river water temperatures.

The first implication would be the possibility that total supply capacity might drop below TVA's target reserve margin of $15 \%$ capacity above peak demand, at least in the short run. In most cases, TVA would have coping strategies available; however, heat wave temperature impacts on generation, as well as heat wave demand for electricity, could pose a non-zero risk of very short-term blackouts in the lower Cumberland Valley area in the absence of resource planning for this climate change scenario. This is especially true if the heat wave spreads over a large enough region that only limited power is immediately available on the wholesale electricity market to respond to very rapid shortfalls in supply capacity.

\subsubsection{3 "Other" electricity production sources}

For the purposes of this report, it is assumed that renewable energy sources of power generation such as photovoltaics and windpower would not be affected by the drought and heat wave. 


\subsubsection{Summary}

Climate change analysis in the US National Climate Assessment of 2014 project shows that the southeastern United States will be subject to an increased likelihood of seasonal droughts and seasonal heat waves in the mid- to long-term future. Under the highest global greenhouse gas emissions scenario, by midcentury the number of days in Knoxville with a maximum temperature over $95^{\circ} \mathrm{F}$ is projected to increase from a historical average of fewer than five to more than twenty, annually (Figure 8, Figure 9).

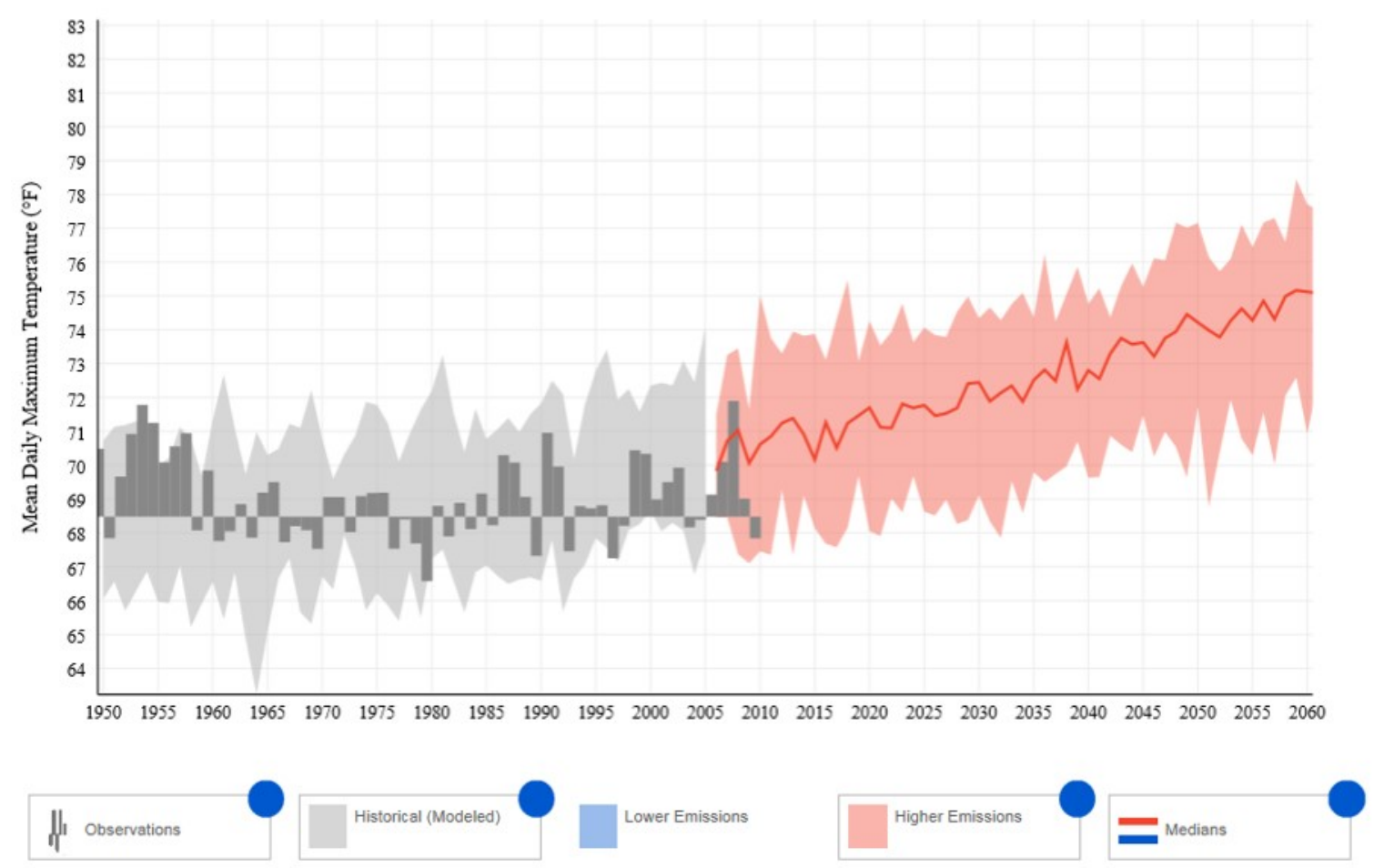

Figure 8. Observed and modeled mean daily maximum temperature for Knox County, Tennessee, under RCP 8.5. Data and image courtesy of the US Climate Data Toolkit (http://toolkit.climate.gov/climate-explorer2/). 


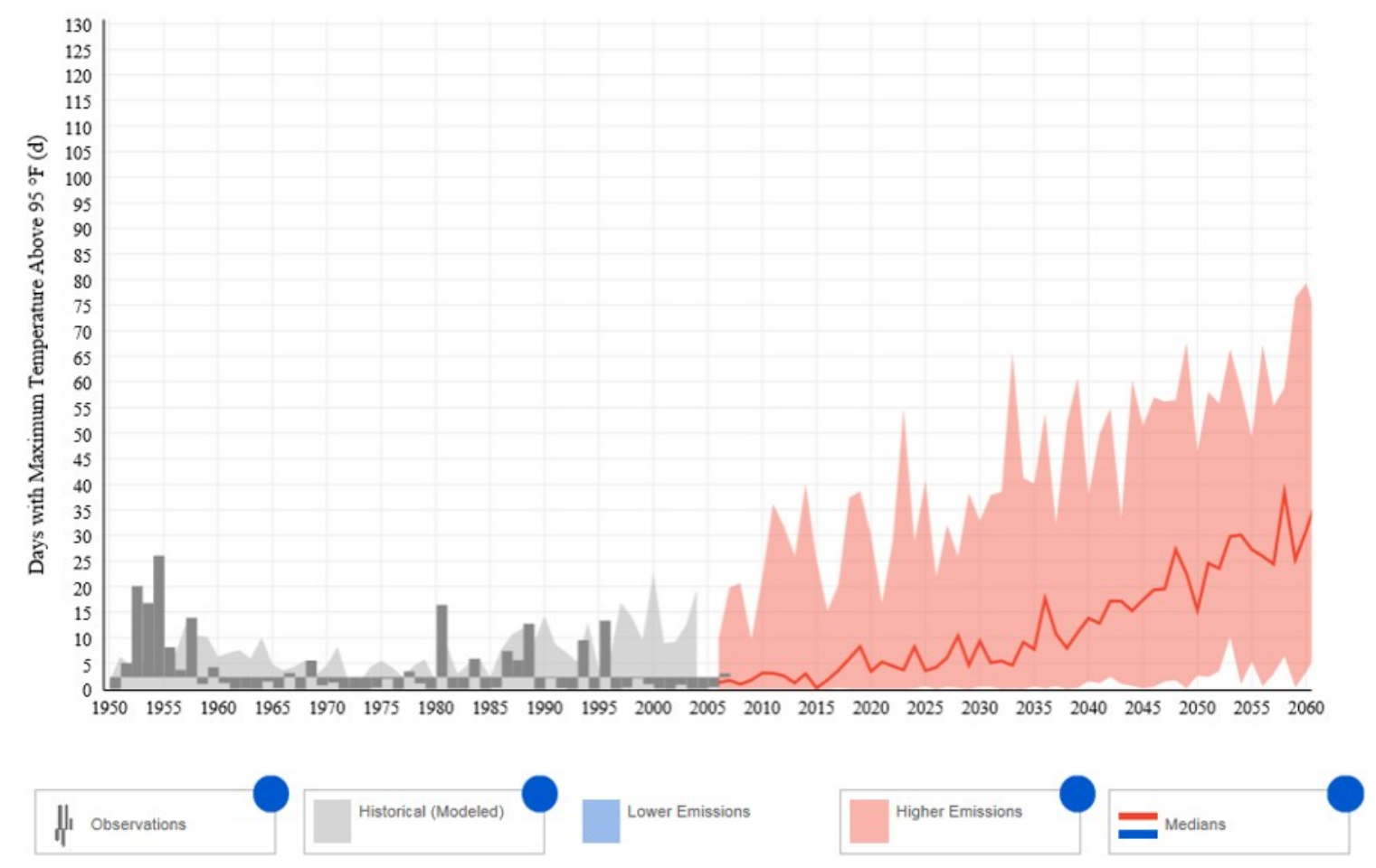

Figure 9. Observed and modeled days with maximum temperature above $95^{\circ} \mathrm{F}$ for Knox County, Tennessee, under RCP 8.5. Data and image courtesy of the US Climate Data Toolkit (http://toolkit.climate.gov/climate-explorer2/).

This preliminary analysis indicates that in absence of integrated resource planning that accounts for climate change, such climate-related extreme events could represent a threat to electricity services in the Cumberland River basin part of the TVA region as soon as the 2050s.

Perhaps as revealing is the finding of the study that several long-term trends for the area would, under the conditions approximated by climate change scenario RCP 8.5 , have serious implications for electricity services in the area by the 2050 s, with or without such extreme events. The dominant trends are warming air temperatures and population growth. Warming air temperatures will mean warmer water, which will significantly stress thermal electricity generation requiring cooling (as well as biota in the river system); and population growth plus warming temperatures will mean significant growth in electricity demand. Given these trends, the main importance of extreme events may be as "tipping points" that push a stressed electricity system into at least short-term trouble unless the resilience of the system to both the long-term trends and the extreme events is substantially enhanced.

\section{COSTS OF IMPACTS}

The estimation of costs associated with the climate change vulnerabilities described in the previous section is limited to order-of-magnitude monetary costs plus other qualitative analysis. In this analysis, we differentiate between costs of electricity shortages and the costs of electricity outages. This is complemented by an estimate of the long-term of costs of climate variability and change, with a specific focus on hydropower (Section 5). 


\subsection{COSTS OF ELECTRICITY SHORTAGES}

The vulnerability analysis of a projected drought plus a projected heat wave indicated the possibility of a significant gap between electricity demand and electricity production capacity in the Cumberland River area of the TVA region. In the worst-case simulation, a $60 \%$ reduction of hydropower generation by and a $40 \%$ reduction in fossil electricity generation by, combined with a 52\% demand increase between 2010 and 2050 and a combined drought and heat wave in 2050, adds up to a $73 \%$ increase in demand compared with 2010 averages (Section 3.2), which would result in a major shortfall in electricity supply. The shortfall caused by increased electricity demand alone during the heat wave period would be 108,400 $\mathrm{MWh}$ day. Supply limitations from elevated stream temperatures and lower water availability would increase this shortfall.

If any supply shortfalls are met by purchases of electricity from the wholesale market, as has frequently been done in the past, the cost of the difference between external purchases and internal generation can be conservatively estimated, assuming (a) a price of $\$ 40 / \mathrm{MWh}$ purchased from the wholesale market (September 2015 average US prices were \$36-\$40, with no drought-related pressures on TVA's demand. Historically, these charges have sometimes been much higher.) and (b) Energy Information Administration (EIA) data on average power plant operating and maintenance expenses for major investor-owned electric utilities in 2012, plus fuel costs.

Table 4 shows the costs of restoring normal power generation levels under current conditions. A total net cost of $\$ 490,358$ per day in substituting wholesale power purchases for internally generated power would, if continued for a number of days, almost certainly require a rate increase by TVA-although it would ensure a continuing flow of electricity to consumers in the Cumberland River basin area. This is a response of current infrastructures to a far-future extreme event scenario, but it provides a very rough ballpark estimate of impact costs on current electricity infrastructures in the absence of future adaptation actions to improve resilience. Also, this does not include a major increase in demand with warming over the decades and with the hypothesized heat wave. Taking an additional demand increase $(108,400$ $\mathrm{MWh}$ /day during the heat wave) into account, the total cost per day to cover a potential shortfall would escalate enormously (an additional cost of $\$ 40 / \mathrm{MWh}$ ), and a possibility of outages would become more of a concern.

Table 4. Cost of restoring normal power generation levels under current conditions

\begin{tabular}{|c|c|c|c|c|}
\hline Fuel source & Quantity needed & External cost & $\begin{array}{c}\text { Estimated } \\
\text { Operations } \\
\text { and } \\
\text { Maintenance } \\
\text { Cost and Fuel }\end{array}$ & Difference \\
\hline Hydro (simulated) & $\begin{array}{l}60 \% \text { of } 914 \mathrm{MW} \\
\text { or } 548 \mathrm{MW}\end{array}$ & $\$ 40 / \mathrm{MWh}$ & $\$ 11.3 / \mathrm{MWh}$ & $\begin{array}{c}\$ 28.7 / \mathrm{MWh} \times 548= \\
\$ 15,728 / \text { hour or } \\
\sim \$ 377,462 / \text { day }\end{array}$ \\
\hline Fossil & $\begin{array}{c}40 \% \text { of } 4,200 \mathrm{MW} \\
\text { or } 1,680 \mathrm{MW}\end{array}$ & $\$ 40 / \mathrm{MWh}$ & $\$ 37.20 / \mathrm{MWh}$ & $\begin{array}{c}\$ 2.80 / \mathrm{MWh} \times 1,680= \\
\$ 4,704 / \text { hour or } \\
\$ 112,896 / \text { day }\end{array}$ \\
\hline Total & & & & $\sim \$ 490,358 /$ day \\
\hline
\end{tabular}

\subsection{COSTS OF ELECTRICITY OUTAGES}

Historically, most electricity outages in the US Southeast have been associated with storms or floods that cause damage to transmission and distribution systems. Droughts and heat waves are not considered 
serious direct threats to T\&D systems, although temperature levels can affect transmission efficiency and distribution system viability.

This analysis does not project blackouts other than in a worst case of a rather sudden shutdown of a significant amount of fossil generation capacity, together with short-term supply scarcity in the spot market. In such an event, however, costs would include costs to TVA from lost revenues from electricity sales and also costs to customers who lose power.

One indication of costs to TVA from a one-hour electricity outage would be the loss of revenues from the Nashville portion of the Cumberland River basin area, which accounts for 9\% of TVA's sales. In 2014, Nashville consumed 34.2 million $\mathrm{kWh}$ per day at an average of $\$ 0.1014 / \mathrm{kWh}$. This adds up to $\$ 128,250 /$ hour in revenues, or $\$ 384,750$ for a three-hour blackout.

At least as important from a regional point of view are costs to consumers from power interruptions. A recent report by the Congressional Research Service estimated the average cost of al h outage for manufacturing and digital economy consumers is $\$ 7,795$ per consumer, but the cost for $5 \%$ of industrial and commercial customers can be much greater, up to $\$ 1.5 \mathrm{M}$ per customer in extreme cases (Campbell, 2012). This is roughly consistent with survey-based estimates published in 2015 by Lawrence Berkeley National Laboratory (Sullivan et al., 2015).

\subsection{SUMMARY}

These calculations are not intended to be interpreted as forecasts of the future, even in the event of a serious drought plus a severe heat wave. However, they do provide order-of-magnitude monetary cost estimates of current system vulnerabilities in the Cumberland River basin area to a plausible extreme event in the moderately far-distant future if no adaptation investments are undertaken. The fact the numbers are so high, however, indicates that resilience to longer-term climate-related extreme weather events represents a serious risk that is worthy of consideration for long-term planning.

\section{MODELING CLIMATE CHANGE COSTS-A CASE STUDY FOCUSED ON TVA HYDROPOWER}

The analysis in Section 4 estimates the potential costs of electricity shortfalls arising from a future discrete extreme event characterized by high temperatures (i.e., a heat wave) and drought conditions. In this section, this analysis is expanded to (a) illustrate a coherent modeling approach to estimate costs of climate change and extreme events and (b) to consider the long-term consequences of changes in climate in a manner that represents both changes in climate for the year 2050 as well as interannual variability in climatic conditions. In so doing, the case study focuses specifically on hydropower generation in the TVA region.

\subsection{CONTEXT}

Hydropower accounts for approximately $10 \%$ of TVA's generation in a typical year (Table 4). Previous studies have demonstrated a general linear relationship between streamflow and hydropower generation (DOE, 2013). This suggests a high degree of sensitivity to climate conditions because of the effects of changes in rainfall, runoff, and temperature on streamflow. As a consequence, hydropower generation may be disproportionately affected during conditions of drought and/or extreme temperature relative to other types of generation (e.g., fossil or other renewables). With climate change projected to increase temperatures and, potentially, the frequency, intensity, and duration of drought conditions, both transient and long-term adverse impacts are anticipated for hydropower. 
This case study presents a simple modeling approach for estimating the sensitivity of hydropower generation to climate conditions and then applies that approach to explore the implications of a climate change scenario. The case study focuses on the hydropower facilities of the TVA region with a particular emphasis on the impacts of climate change on annual and summer generation and the economic value of that generation. Rather than estimating the generation shortfalls of a particular event, this case study estimates impacts of climate change over a 43 year period to capture inter-annual variability in climate conditions (including the effects of extreme events such as a heatwave) as well as long-term shifts in mean conditions. This enables the costs of extreme events to be placed in a larger context to better evaluate the needs and potential benefits of interventions. To maintain consistency, this case study builds on the climate change analyses and assumptions reported elsewhere in this report (Appendix C).

\subsection{MODELING APPROACH}

The relationships among temperature, streamflow, and generation anomalies were modeled using a graphical modeling approach known as a Bayesian belief network (BBN). A BBN graphically illustrates the conceptual linkages between each dependent and independent variable. Each variable is represented as a node with multiple states. To learn the relationships among the various variables (i.e., "training" the model), an expectation maximization algorithm was applied. The algorithm calculated the conditional probabilities between each variable and variable state in the network model based on historical observations of monthly, seasonal, and annual temperature, streamflow, and generation for the 29 hydropower facilities in the TVA region. To enable comparison among the different hydropower facilities, variable anomalies were used to train the model rather than absolute values, which vary significantly from one facility to the next. Anomalies were expressed as standard scores, or z-scores, which were defined using equation (3):

$$
Z=\frac{X-\mu}{\sigma}
$$

where $z=$ the standard score, $X=$ the monthly variable value in a given year, $\mu=$ monthly mean value over 43 years (1970-2013), and $\sigma=$ the standard deviation of the monthly mean value.

Once trained, the model was used to generate updated estimates of generation anamolies in response to changes in any of the input variables. For this case study, projections of changes in temperature and rainfall based on the downscaled climate modeling presented in Section 2.2 were used as input to project future generation anamalies in resposne to climate change (Appendix C). Although the model output consists of z-scores for generation, z-scores could be converted back into absolute generation using the coresponding historical monthly or annual mean and standard deviation associated with each facility (Appendix C).

\subsection{RESULTS}

Both observed and modeled summer generation in the TVA region reflect the high degree of inter-annual variability that exists as a consequence of variability in climatic conditions as well as the implications of those conditions for electricity demand. Among the 43 years of observations, annual generation anomalies ranged from approximately $\pm 6 \mathrm{GWh}$, whereas generation for summer months ranged from approximately $\pm 1.5 \mathrm{GWh}$ (Figure 10). The Bayesian model of historical conditions yielded quite similar results, but with slightly lower maximum values and slightly higher minimum values. In addition, 2013 stands out as a year when generation was particularly high, while 2007 was particularly low. These large anomalies were directly attributable to streamflow conditions. For example, during the months of June, July, and August of 2007, hydropower facilities in the TVA region experienced negative monthly streamflow anomalies greater than 1 standard deviation from the mean $85 \%$ of the time. Meanwhile, in 2013, hydropower 
facilities experienced positive monthly streamflow anomalies of greater than 1 standard deviation $84 \%$ of the time. Hence, 2013 was a record high year for hydropower electricity generation for TVA (Figure 10).
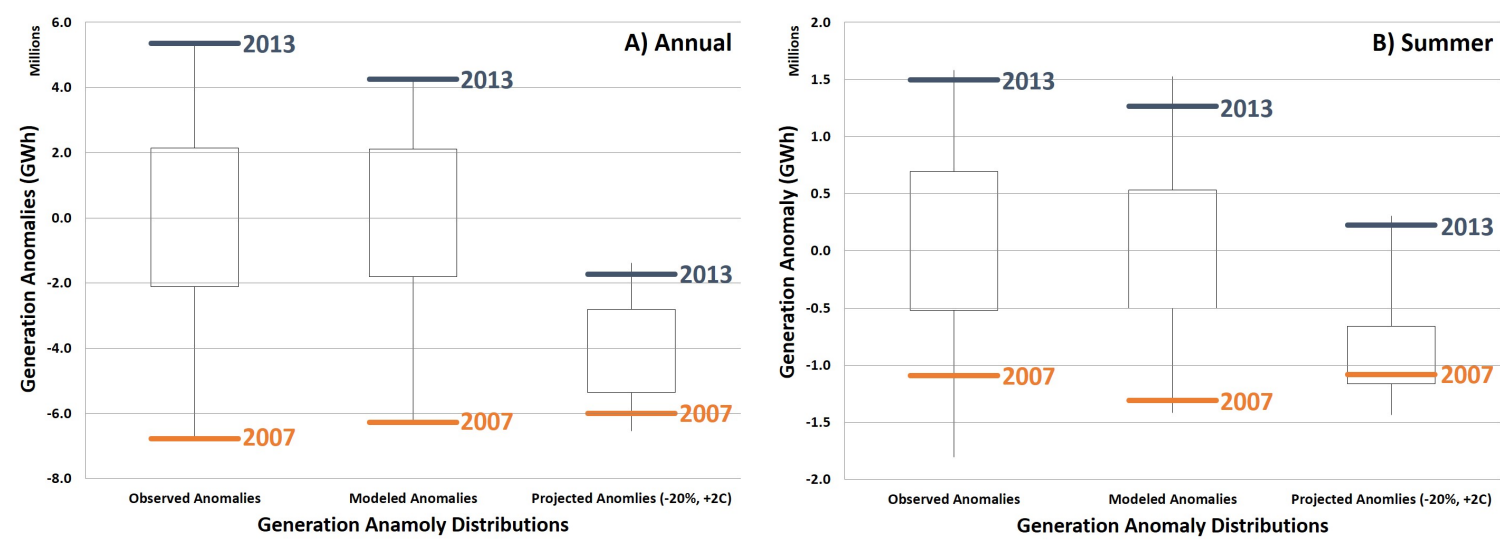

Figure 10. Estimates of (A) annual and (B) summer absolute generation anomalies based on historical conditions (observed and modeled) and a climate change scenario $\left(-20 \%\right.$ rainfall and $2^{\circ} \mathrm{C}$ increase).

Box and whisker plots represent the minimum and maximum values (vertical lines or whiskers) and the 25th and 75th percentile (box) results for 43 years (1970-2013). In addition, results just for the specific years 2013 (a wet year) and 2007 (a dry year) are presented in the figure as horizontal lines (blue $=2013$, orange $=$ 2007).

When historical data were adjusted based on projected midcentury climate conditions and the BBN model was rerun, results indicated such a climate change would significantly shift the distribution of generation anomalies compared with historical conditions (Figure 10). In the climate change scenario, annual generation anomalies ranged from $-2 \mathrm{GWh}$ to $-6 \mathrm{GWh}$, and summer anomalies ranged from $0.25 \mathrm{GWh}$ to $-1.5 \mathrm{GWh}$. Hence, hydropower generation in most years and summers is projected to decline significantly. Relative to historical conditions, it would take an abnormally wet year, like a repeat of 2013, for a positive generation anomaly to be experienced.

When these generation impacts were translated into dollar values, the implications of the climate change scenario for revenue were readily apparent (Figure 11). At present, historical data demonstrates economic gains in good years are roughly in balance with losses in bad years. For example, while the anomalously high generation during 2013 translates into $\$ 421,000 /$ day of revenue (assuming a market for that excess generation), the low generation during 2007 represented comparable losses of $\$ 532,000$ /day relative to an average year's generation (Figure 11).

Isolating the impacts for the summer months, the values for 2013 and 2007 were $+\$ 467,000 /$ day and $-\$ 339,000 /$ day, respectively. However, for the climate change scenario, losses are anticipated to occur on both an annual and seasonal basis relative to historical conditions. Results indicate the long-term impacts of climate change could shift the value of typical summer generation anomalies (middle 50th percentile) in the TVA region from $+\$ 217,000 /$ day to $-\$ 162,000 /$ day to $-\$ 205,000 /$ day to $-\$ 363,000 /$ day. On an annual basis, the shift in the value of generation anomalies was anticipated to be from $+\$ 169,000 /$ day to $-\$ 166,000 /$ day at present to $-\$ 221,000 /$ day to $-421,000 /$ day. Over the course of an entire year, these impacts could equate to $\$ 80 \mathrm{M}-\$ 153 \mathrm{M}$ in lost revenue. 

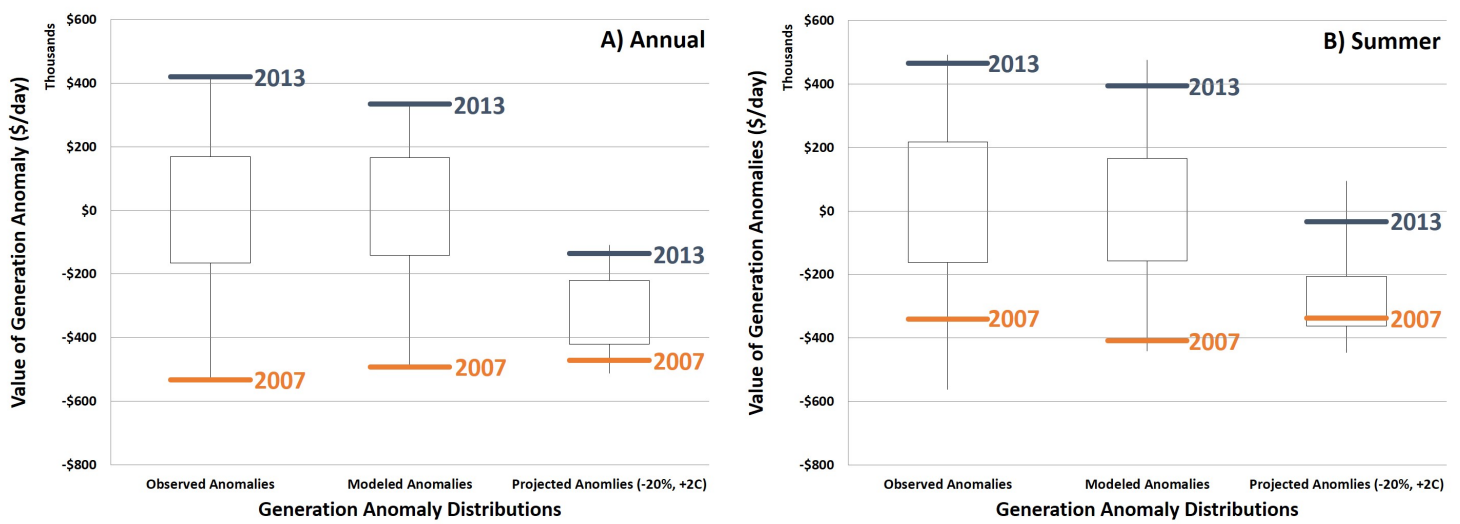

Figure 11. Estimates of the (A) annual and (B) summer economic value of summer generation anomalies based on historical conditions (observed and modeled) and a climate change scenario

$\left(-20 \%\right.$ rainfall and $2^{\circ} \mathrm{C}$ increase). Box and whisker plots represent the minimum and maximum monthly values (vertical lines or "whiskers") and the 25th and 75th percentile (box) results for 43 years (1970-2013). In addition, results just for the specific years 2013 (a wet year) and 2007 (a dry year) are presented in the figure as horizontal lines (blue $=2013$, orange $=2007$ ).

\subsection{DISCUSSION}

Because of the linear relationship between streamflow and generation, it is possible to develop relatively simple but robust empirical models for hydropower generation and update those models with assumptions about future climate change to explore potential impacts. Furthermore, because electricity generation is a revenue stream for energy utilities, impacts on generation have direct implications for utility earnings and profit. The case study described here illustrates one method for estimating costs and serves as a first step in evaluating opportunities for potential interventions that would reduce climate change effects on generation, augment generation (e.g., with other forms of generation), or both to maintain supply.

In addition, this analysis found these projected impacts are not the consequence of a single abnormally dry year, but these impacts are expected to be a regular feature of electricity generation in the TVA region. Although the simple model applied here does not effectively capture increases in drought severity beyond historical measurements, for the climate change scenario applied, the consequences to generation of such particular extreme years would be amplified as well. The US National Climate Assessment, for example, reported extreme weather events, such as heat waves and droughts, are projected to increase in frequency, intensity, and duration (Walsh et al., 2014). Model results consistently indicate the anticipated reduction in generation associated with the climate change scenario would contribute to opportunity costs of hundreds of thousands of dollars per day from lost electricity sales revenue.

These estimates of the costs of climate change impacts are based on a simple empirical model of hydropower generation that only account for the supply side of generation. Process-based, operational models of hydropower facilities, such as those commonly used by TVA and other utilities, are capable of producing far more refined estimates of generation, facility responses to environmental conditions, as well as management interventions that can be used to maintain the reliability of generation. Furthermore, as discussed elsewhere in this report, power generation is also affected by demand, which is often influenced by environmental conditions. Demand also affects electricity prices and, as a result, the level of revenue that utilities can collect from electricity sales. Better integration of climate change impacts on supply and demand across managed generation systems would enable more comprehensive accounting of the potential costs and benefits of mechanisms for coping with, or adapting to, impacts. 
Despite these caveats, this case study illustrates the approximate magnitude of declines in hydropower generation in response to long-term shifts in climate conditions as well as estimates of the order-ofmagnitude market costs of those declines. This information can be compared with the costs of constructing or deploying possible management interventions - from river operations, to reservoir expansion, to generation expansion, to demand management - in a cost-benefit calculation. Persistent declines in hydropower over summer months when electricity demand is high might represent hundreds of millions to billions of dollars of lost revenue over the long-term. In addition, shortfalls in the baseload generation provided by hydropower could reduce the reserve margin for TVA, forcing expansions of generation capacity to meet regulatory requirements. Because this case study only focuses on generation and not demand, no attempt was made to explore impacts to the reserve margin. However, because climate change and its long-term impacts were not a factor incorporated into supply and demand estimates in TVA's Integrated Resource Plan (2015), additional interventions might be necessary to maintain the supply reliability, assuming the climate scenario used manifests and no other changes in the system are made.

\section{ADAPTATION SOLUTIONS FOR RESILIENCE}

The costs of climate change impacts can be reduced by employing adaptation strategies and actions that add resilience to the electricity system. In general, adaptation options include several categories that are considered in TVA's detailed IRP, which uses 2033 as a time horizon rather than 2050-2059:

\subsection{ENHANCED EFFICIENCY (EE) IN ELECTRICITY USE AND SYSTEM OPERATION}

TVA has active and effective programs to assist customers in improving the efficiency of their electricity use, which reduces generation requirements. The IRP indicates the cost of enhanced efficiency (EE) programs is roughly comparable to building new natural gas combined cycle (NGCC) capacity, with lower levels of uncertainty regarding potential benefits. However, this adaptation can be expensive if pushed to a maximum level.

Electric utilities nationally are pursuing electronic conditioning and controls of electricity operation, such as smart meters and dispatching for delivery of electricity finely matched to needs. TVA has estimated that costs to distribution systems for full implementation of these "smart grid" systems would be high, increasing monthly utility bills; further, consumer acceptance is likely to emerge slowly. Of course, as such technologies decline in cost over time, so too would the cost of full implementation.

Note that "TVA considers flexibility - the ability of the system to respond to load swings - as a key future consideration for long-range resource planning" (IRP 102). This is another option that increases the resilience of an electricity system, and as long as the net cost is not too high, it is nearly always an attractive option. Alternatives, all of which involve some costs, include increased energy storage and higher reserve margins.

\section{CHANGES IN THERMAL ELECTRIC POWER PLANT COOLING APPROACHES}

Another option is to move large base-load coal and nuclear units to cooling towers or combined cooling towers and once-through-cooling (OTC). This option reduces both water withdrawal from and heat rejection to the river, lake, or other body of water serving a unit or plant, supporting continued operation and compliance with water-body temperature regulations.

In multi-unit plants, the strategy could be to continue OTC for older, smaller, lower capacity factor units, and add cooling towers to the newer, larger, higher capacity factor units. This could also bring retrofitted units into EPA Clean Water Act Section 316(b) compliance. 
This strategy would clearly be effective, but it is an expensive option. For example, it would take an estimated \$300M to retrofit the 2600 MW Cumberland plant, which is the largest plant in the Cumberland River basin.

\section{NATURAL GAS IN PLACE OF COAL}

One could add new NGCC capacity, possibly designed to allow either combined cycle (CC) or combustion turbine only (CT-only) operation. In CC-mode, efficiency is higher than in steam-electric units, reducing cooling water requirements proportionally. In CT-only mode, the operator still gets more than $50 \%$ of nameplate capacity with essentially no cooling water requirement. Capital costs of NGCC for each MW of added capacity are relatively low (Error! Reference source not found.).

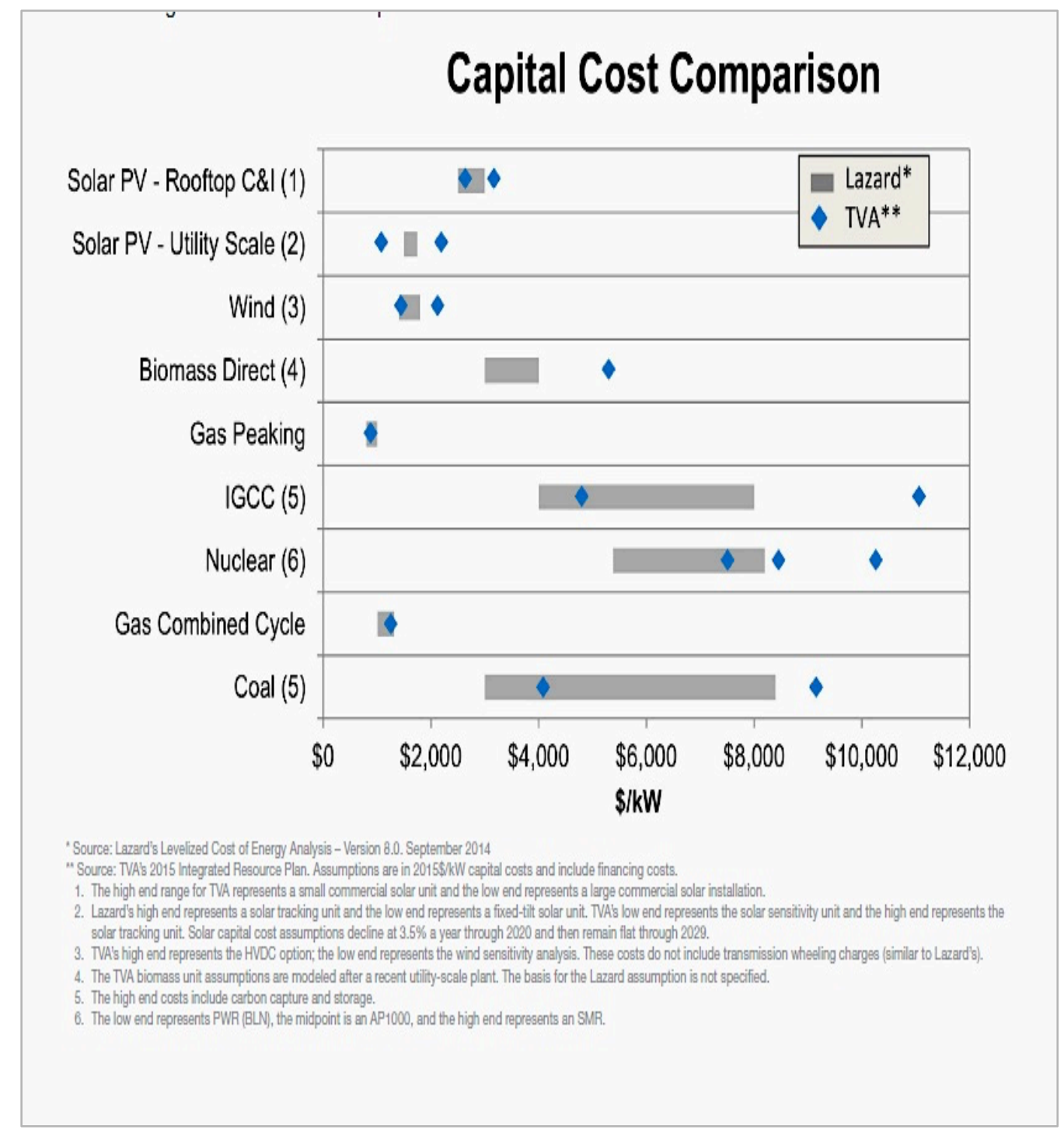

Figure 12. Estimated capital costs of electricity generation options. Courtesy of Tennessee Valley Authority (TVA), Integrated Resource Plan (2015).

Natural gas in place of coal increases in the use of alternative electricity generation technologies (i.e., renewable energy resource/technology combinations that are not water-consumptive in operation). Capital costs are generally relatively low (Error! Reference source not found.), but capacity factors for wind 
and solar plants reduce their contributions to the total utility load. Some renewables-based generation can be variable (e.g., wind), driving a need for greater storage capacity, demand-side flexibility, or other dispatchable reserve generation. This becomes more of an issue as renewables become a larger portion of the generating mix on a grid.

Increased energy storage to add resilience to intermittent generation and to changes in conditions, such as the current Raccoon Valley pumped storage unit. Costs are highly dependent on location, especially for pumped hydropower projects, but DOE-EPRI estimates total plant costs $\$ 1,850-\$ 2,7000 / \mathrm{kW}$. Other sources show somewhat higher costs.

Expansions in long-distance interconnections improve the ability to move power as needed, taking advantage of time-zone impacts on load and variances in weather and cooling water (OTC) across a larger, more diverse geography than currently exists. The IRP's data on capital costs of the various options are shown in Error! Reference source not found.

\section{BENEFITS OF CLIMATE RESILIENCE SOLUTIONS}

Cost-benefit analysis is the process of assigning monetary values to costs and benefits and comparing the net present value of longer-term value earned, damages avoided, or both over the lifetime of the asset. In principle, climate change adaptation measures reduce the impact costs due to the resilience investment. The net present value of future benefits minus costs and the benefit-cost ratio can be calculated using a selected discount rate. Financing costs can also be considered. Selection of discount rates can be controversial, but their net effect is to reduce the net present value of an investment, which may not payoff until the relatively distant future.

It is challenging to estimate monetary values for benefits from resilience investments to minimize uncertain long-range risks, even if the long-term risks appear substantial. In conventional cost-benefit analysis, future benefits are discounted so that their projected net present value decreases through time, and risk reduction benefits that are uncertain must be further reduced by an estimate of the probability of the occurrence of the threat. As a result, the net present value of long-term benefits from present day investments will always be relatively small. Moreover, changes in energy systems over periods of decades are likely to be significant, rendering estimates of benefit calculations based on current knowledge and conditions at least somewhat inaccurate.

For example, the net present value of a $\$ 300 \mathrm{M}$ benefit after 30 years, assuming a discount rate of $4 \%$, is $\$ 92.5 \mathrm{M}\left[\left(300 \times 10^{6}\right) /(1.04)^{30}\right]$. Any present-day investment of more than $\$ 92.5 \mathrm{M}$ to achieve that future benefit would, according to cost-benefit analysis, be excessive. If the probability of the threat occurrence addressed by the current investment is 0.5 , the net present value is cut in half.

This means that current or near-future investments in resilience concerned with long-term vulnerabilities and uncertain threats are more readily justified if they also offer the prospect of other benefits ("cobenefits"), particularly in the nearer term.

Because resilience to impacts of climate change and associated extreme weather events aims to reduce vulnerabilities (a) over a variety of time scales to (b) possible threats with uncertain magnitude and timing and (c) whose nature may be at least partly qualitative, formal cost-benefit analysis is challenging to apply to resilience risk-benefit analysis. However, cost-benefit analysis can be a useful tool, particularly during preliminary analyses, and it is increasingly of interest to utilities aiming to demonstrate to economic regulators the net benefits of proposed projects for customers, or more broadly, society. 


\subsection{TVA'S COST-RISK-BENEFIT ANALYSIS}

TVA's IRP considers costs, risks, and benefits of alternative investment and planning strategies for the future (up to 2033) (Table 5), with an emphasis on a need to ensure not only adequate supply given anticipated growth in demand, but also a target reserve margin of $15 \%$ to protect against surprise risks. Attributes of the strategies include assumptions about the prospects for different types of generation (i.e., nuclear energy, the retirement or replacement of coal, expansions of natural gas and hydropower, and renewable energy at a utility scale) as well as energy efficiency, distributed generation, and new energy storage. Specific considerations include carbon dioxide emissions, water consumption, waste, risk exposure, flexibility, cost, and valley economics, using scorecards and scoring metrics. Included in the plan are sensitivity analyses with different assumptions about technology roles, demands, prices, and policy conditions.

Table 5. Tennessee Valley Authority planning strategies and their key characteristics (TVA, 2015)

\begin{tabular}{l|ll}
\multicolumn{1}{c|}{$\begin{array}{c}\text { Strategy } \\
\text { Strategy A }\end{array}$} & \multicolumn{1}{|c}{ Name } & \multicolumn{1}{c}{ Key characteristics } \\
\hline Strategy B & $\begin{array}{l}\text { Meet an emissions } \\
\text { target }\end{array}$ & $\begin{array}{l}\text { Least cost optimization; energy efficiency/renewables selectable } \\
\text { Resources selected to create lower emitting portfolio based on } \\
\text { an emission rate target or level using } \mathrm{CO}_{2} \text { as the emissions } \\
\text { metric }\end{array}$ \\
\hline Strategy C & $\begin{array}{l}\text { Focus on long-term, } \\
\text { market supplied } \\
\text { resources }\end{array}$ & $\begin{array}{l}\text { Most new capacity needs met using longer-term PPA or other } \\
\text { bilateral arrangements; TVA makes a minimal investment in } \\
\text { owned assets }\end{array}$ \\
\hline Strategy D & $\begin{array}{l}\text { Maximize energy } \\
\text { efficiency }\end{array}$ & $\begin{array}{l}\text { Majority of capacity needs are met by setting an annual energy } \\
\text { target for energy efficiency(priority resource to fill the energy } \\
\text { gap); other resources selected to serve remaining need }\end{array}$ \\
\hline Strategy E & Maximize renewables & $\begin{array}{l}\text { Enforce near-term and long-term renewable energy targets; meet } \\
\text { targets with lowest cost combination of renewables; hydropower } \\
\text { is included as a renewable option along with biomass, wind, and } \\
\text { solar }\end{array}$ \\
\hline
\end{tabular}

To address uncertainty in exogenous conditions, the IRP also considers five alternative scenarios that could emerge in coming decades to affect energy demand and the incentives for different types of generation (Table 6). This includes different assumptions about future population growth, economic growth, carbon constraints, and penetration of distribution energy. However, none of these scenarios specifically address assumptions about climate change or climate-related extreme weather events. The IRP includes a detailed cost and risk assessment of each of these five scenarios for each of the planning strategies future (Figure 13). 
Table 6. Tennessee Valley Authority planning scenarios and their key characteristics

\begin{tabular}{|c|c|c|}
\hline Scenario & Name & Key characteristics \\
\hline Scenario 1 & $\begin{array}{l}\text { Current } \\
\text { outlook }\end{array}$ & $\begin{array}{l}\text { The outlook for the future which TVA is currently using for resource } \\
\text { planning studies }\end{array}$ \\
\hline Scenario 2 & $\begin{array}{l}\text { Stagnant } \\
\text { economy }\end{array}$ & $\begin{array}{l}\text { Stagnant economy results in flat to negative growth, delaying the need for } \\
\text { new generation }\end{array}$ \\
\hline Scenario 3 & $\begin{array}{l}\text { Growth } \\
\text { economy }\end{array}$ & $\begin{array}{l}\text { Rapid economic growth translates into higher than forecasted energy sales } \\
\text { and resource expansion }\end{array}$ \\
\hline Scenario 4 & $\begin{array}{l}\text { De-carbonized } \\
\text { future }\end{array}$ & $\begin{array}{l}\text { Increasing climate-driven effects create strong federal push to curb } \\
\text { greenhouse gas emissions; new legislation caps and penalizes } \mathrm{CO}_{2} \\
\text { emissions from the utility industry and incentivizes non-emitting } \\
\text { technologies }\end{array}$ \\
\hline Scenario 5 & $\begin{array}{l}\text { Distributed } \\
\text { marketplace }\end{array}$ & $\begin{array}{l}\text { Customers' awareness of growing competitive energy markets and the rapid } \\
\text { advance in energy technologies produce unexpected high penetration rates } \\
\text { in distributed generation and energy efficiency. TVA assumes } \\
\text { responsibility to serve the net customer load (no backup for any customer- } \\
\text { owned resources) }\end{array}$ \\
\hline
\end{tabular}

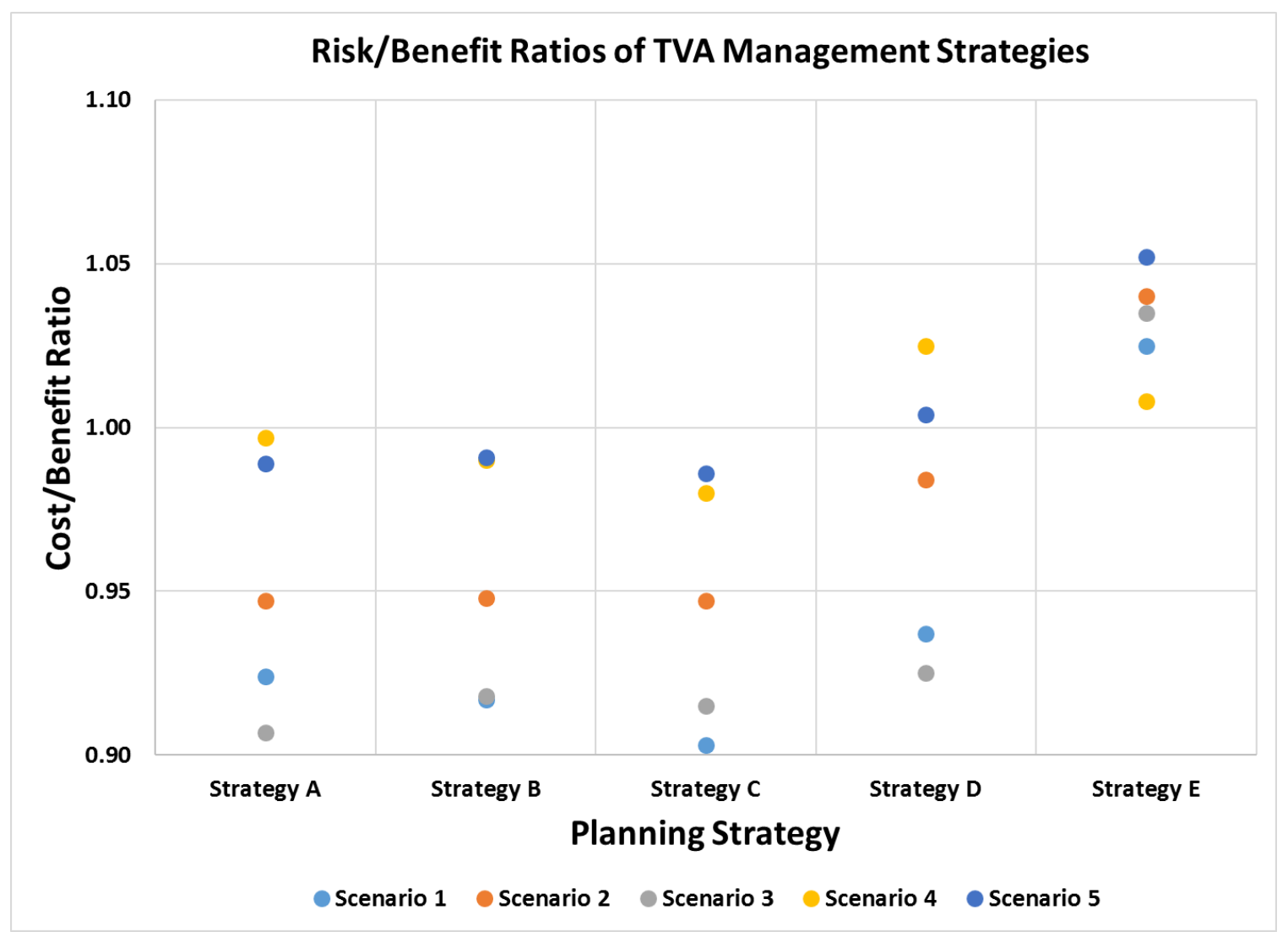

Figure 13. Risk/benefit ratios for each planning strategy. Adapted from Tennessee Valley Authority (TVA), Integrated Resource Plan (2015). 


\subsection{IMPLICATIONS OF TVA'S ANALYSIS}

Given a projected level of demand and a projected set of policy conditions, TVA's cost-risk-benefit analysis estimates a risk/benefit ratio (Figure 13) in which greater benefits are equated to lower risks. In general, technology and resource options with relatively low capital costs (Error! Reference source not found.) and with a relatively high capacity factor (i.e., the proportion of time power is generated) are ranked as better. For instance, natural gas combined cycle is ranked highly on both criteria, whereas most renewable energy sources are high on the first but low on the second. Energy efficiency is included in all five scenarios, but "maximizing energy efficiency" is judged to offer lower net benefits than the first three options.

\subsection{COSTS AND RESILIENCE BENEFITS OF ADAPTATIONS IN THE CUMBERLAND RIVER BASIN AREA RELATED TO FUTURE THREATS}

TVA's plan does not forecast as far as the 2050s, but the preceding analysis suggests the two most salient threats to TVA for a severe, protracted drought and a severe heat wave in the 2050 s time period are (a) projections of electricity demand growth because of population expansion and warming from climate change, and (b) a dependence on ambient surface water bodies for cooling water for thermal power plants, when surface water sources will be warming from decades of climate change.

\subsubsection{Resilience to demand growth}

TVA's IRP is centrally focused on resilience to demand growth out to 2033, and TVA will continue to plan for capacity additions and revitalization to ensure sufficient electricity supplies and also a sufficient capacity margin to address all contingencies. From a cost-benefit perspective, TVA's plan identifies the most promising directions for enhancing resilience to demand growth are least cost optimization deploying a range of strategies, adding thermal electricity capacity with emphasis on natural gas as an energy source, enhancing electricity-use efficiency, increasing energy storage capacities, and possibly increasing the reserve capacity margin. Another option is to significantly increase the share of renewable energy and other distributed energy sources in the TVA electricity generation portfolio, but the analysis concluded the financial risks would be too high because of capacity factor issues (unless political, technological, or economic conditions were to change). However, with a greater likelihood of more frequent and intense extreme heat events, investments in energy efficiency would increase in value as a tool for reducing risks associated with heat-related demand growth.

\subsubsection{Resilience to warming surface water sources for cooling}

The most promising direction to address the threat of warming surface water sources for cooling is to adopt strategies over the next 3 decades that reduce requirements for cooling water from surface water sources, either through increased use of cooling towers or through shifts toward power generation options that do not require cooling. As a result, the greater use of energy efficiency and investments in certain renewable energy resources could become more valuable to TVA, as a part of their larger calculation of cost-risk-benefit analysis.

\subsection{SUMMARY OF THE COST-BENEFIT ANALYSIS EXPERIENCE}

This preliminary TVA case study applied cost-benefit analysis to develop order-of-magnitude results. Additional analysis is necessary to conduce comprehensive and more detailed cost-benefit analyses of resilience enhancement options for the Cumberland River basin. The basin is faced with threats from both gradual climate change and extreme event scenarios, including a major drought and a severe heat wave in the 2050 s. 
This exercise, which was informed by TVA's formal resource planning, provides valuable lessons about what is possible with cost-benefit analysis for this kind of resilience question. Cost-benefit analysis requires quantitative estimates of the monetary value of costs and benefits of a proposed action, along with specification of a time horizon for realizing the benefits.

Formal cost-benefit analysis is a useful tool for assessing future infrastructure needs, but the process is limited in what it is capable of quantifying. This kind of analysis can only quantify projections of threats to electricity and infrastructures based on specific scenario parameters. Vulnerabilities to threats can be quantified using scenarios with current technology, and case-by-case differences and utility management strategies can be applied. Impacts based on current or recent system conditions and facilities can be successfully estimated, and the costs and benefits of most adaption options can be calculated.

It is harder to quantify vulnerabilities of infrastructures for longer time scales. Probabilities of all threats cannot be reflected in scenario-based analysis, and uncertainty bands expand as the time horizon increases. Contextual parameters - such as electricity demand, economic and policy conditions, and technological change - are challenging to account for in this type of analysis as well. Quantification of assumptions related to risk exposure, desired flexibility, regional economic health, and environmental management objections, such as water availability, are also difficult to quantify.

Cost-benefit analysis, combined with risk assessment, is a useful tool to explore strategies for resilience enhancement of electricity systems facing known future threats and challenges. This method is generally most useful for estimating the value of resilience investments over the relatively near future, such as the 20 year time horizon used in TVA's IRP. Even then, cost-benefit analysis is nearly always applied in connection with a number of alternative scenarios to show a range of possible results, rather than a single result. For threats in the longer term (e.g., 40 years from now), it is more difficult to inform decisions because of uncertainties about the magnitude and timing of threats. In fact, it is often necessary to develop plausible scenarios, extrapolate from historical experiences, or use other subjective approaches to characterize the nature of future threats. As a result, cost-benefit analysis for longer-term resilience options is more challenging, but it remains a useful tool for enabling decision-making strategies that minimize risk and favor investments with multiple co-benefits. Further efforts are needed to develop and demonstrate effective applications for cost-benefit analysis to inform planning for climate resilience investments. This is increasingly of interest to utilities aiming to demonstrate to economic regulators the net benefits of proposed projects for customers, or more broadly, society.

\section{REFERENCES}

Allen, M. R., S. J. Fernandez, J. S. Fu, M. Olama. 2016. "Impacts of Climate Change on Sub-Regional Electricity Demand and Distribution in the Southern United States." Nature Energy. 16103: 1-9. doi: 10.1038/NENERGY.2016.103.

Ashfaq, M., S. Ghosh, S.-C. Kao, L. Bowling, P. Mote, D. Touma, S. Rauscher, and N. Diffenbaugh. 2013. "Near-Term Acceleration of Hydroclimatic Change in the Western U.S." J. Geophys. Res. 118: 10,676-10,693. doi: 10.1002/jgrd.50816.

Beigi, E., and F. Tsai. 2014. "GIS-Based Water Budget Framework for High-Resolution Groundwater Recharge Estimation of Large-Scale Humid Regions.” J. Hydrol. Eng. 19 (8): 05014004. doi: 10.1061/(ASCE)HE.1943-5584.0000993.

Bhaduri B. L., E. Bright, P. Coleman, and M. Urban. 2007. "LandScan USA: A High Resolution Geospatioal and Temporal Modeling Approach for Population Distribution and Dynamics." GeoJournal. 69 (1): 103-117. 
Brakebill, J. W., D. M. Wolock, and S. E. Terziotti. 2011. "Digital Hydrologic Networks Supporting Applications Related to Spatially Referenced Regression Modeling." J. Am. Water Resour. Assoc. 47 (5): 916-932. doi: 10.1111/j.1752-1688.2011.00578.x.

Brashears, E. 2007. "Obstacle to More Power: Hot Water: River Temperature So High that Duke Energy Curtails Work at 2 Plants." Charlotte Observer, August 12.

Campbell, R. 2012. Weather-Related Power Outages and Electric System Resiliency. Congressional Research Service. Rep. No. R42686. Library of Congress, Washington DC.

Daly, C., W. P. Gibson, G. H. Taylor, G. L. Johnson, and P. Pasteris. 2002. “A Knowledge-Based Approach to the Statistical Mapping of Climate.” Climate Res. 22: 99-113. doi: 10.3354/cr022099.

Department of Energy. 2013. Effects of Climate Change on Federal Hydropower. US Department of Energy, Washington DC.

Department of Energy. 2015. Quadrennial Energy Review: Energy Transmission, Storage, and Distribution Infrastructure. US Department of Energy, Washington DC. Available at: http://energy.gov/epsa/quadrennial-energy-review-qer.

Energy Information Administration. 2012. Today in Energy. Available at: http://www.eia.gov/todayinenergy/detail.cfm?id=7070.

Environmental Protection Agency and US Geological Survey. 2010. NHDPlus User Guide.

Environmental Protection Agency. Available at: ftp://ftp.horizonsystems.com/NHDPlus/NHDPlusV1/documentation/NHDPLUSV1_UserGuide.pdf.

Electric Power Research Institute. 2009. Potential Impact of Climate Change on Natural Resources in the Tennessee Valley Authority Region. Rep. No. 1020420. Electric Power Research Institute, Palo Alto, CA. Available at: http://www.nrc.gov/docs/ML1328/ML13289A098.pdf.

Grunsky, C. E. 1932. "Evaporation from Lakes and Reservoirs." Monthly Weather Review. January 2-6.

Kao, S.-C., M. Ashfaq, B. S. Naz, R. Uría Martínez, D. Rastogi, R. Mei, Y. Jager, N. M. Samu, and M. J. Sale. 2016. The Second Assessment of the Effects of Climate Change on Federal Hydropower. Rep. No. ORNL/TM-2015/357. Oak Ridge National Laboratory, Oak Ridge, TN.

Kao, S.-C., M. J. Sale, M. Ashfaq, R. Uría Martínez, D. Kaiser, Y. Wei, and N. S. Diffenbaugh. 2015. Projecting Changes in Annual Hydropower Generation Using Regional Runoff Data: An Assessment of the United States Federal Hydropower Plants. Energy. 80: 239-250. doi:10.1016/j.energy.2014.11.066

Kao, S.-C., R. A. McManamay, K. M. Stewart, N. M. Samu, B. Hadjerioua, S. T. DeNeale, D. Yeasmin, M. F. K. Pasha, A. A. Oubeidillah, and B. T. Smith. 2014. New Stream-Reach Development: A Comprehensive Assessment of Hydropower Energy Potential in the United States. Rep. No. GPO DOE/EE-1063. Wind and Water Power Program, Department of Energy, Washington DC.

Lott, J. N. 1994. "The U.S. Summer of 1993: A Sharp Contrast in Weather Extremes." Weather. 49 (11): $370-383$.

McKee, T. B., N. J. Doesken, and J. Kleist. 1993. "The Relationship of Drought Frequency and Duration of Time Scales." Eighth Conference on Applied Climatology, American Meteorological Society, January 17-23, Anaheim, CA, 179-186.

McKee, J. J., A. N. Rose, E. Bright, T. Huynh, and B. Bhaduri. 2015. "A Locally-Adaptive, SpatiallyExplicit Projection of U.S. Population for 2030 and 2050." Proc. Natl. Acad. Sci. 112 (5): 1344-1349. Available at: http://www.pnas.org/content/112/5/1344.full.

Meehl, G. A., and C. Tebaldi. 2004. "More Intense, More Frequent, and Longer Lasting Heat Waves in the 21st century." Science. 305: 994-997. 
Naz, B. S., S.-C. Kao, M. Ashfaq, D. Rastogi, R. Mei, and L. C. Bowling. 2016. "Regional Hydrologic Response to Climate Change in the Conterminous United States Using High-Resolution Hydroclimate Simulations." Global Planet. Change. 143: 100-117. doi: 10.1016/j.gloplacha.2016.06.003.

Peters, G. P., R. M. Andrew, T. Boden, J. G. Canadell, P. Ciais, C. Le Quéré, G. Marland, M. R. Raupach, and C. Wilson. 2013. "The Challenge to Keep Global Warming below $2^{\circ} \mathrm{C}$." Nature Climate Change. 3: 4-6.

Oubeidillah, A. A., S.-C. Kao, M. Ashfaq, B. S. Naz, and G. Tootle. 2014. "A Large-Scale, HighResolution Hydrological Model Parameter Data Set for Climate Change Impact Assessment for the Conterminous US.” Hydrol. Earth Syst. Sci. 18: 67-84. doi: 10.5194/hess-18-67-2014.

Sale, M. J., S.-C. Kao, M. Ashfaq, D. P. Kaiser, R. Uría Martínez, C. Webb, and Y. Wei. 2012. Assessment of the Effects of Climate Change on Federal Hydropower. Rep. No. 2011/251, Oak Ridge National Laboratory, Oak Ridge, TN.

Seager, R., A. Tzanova, and J. Nakamura. 2009. "Drought in the Southeastern United States: Causes, Variability over the Last millennium, and the Potential for Future Hydroclimate Change." Journal of Climate. 22: 5021-5045.

Stern, N., et al. 2006. Stern Review: The Economics of Climate Change. London: HM Treasury.

Sullivan, M. J., J. Schellenberg, and M. Blundell. 2015. "Updated Value of Service Reliability Estimates for Electric Utility Customers in the United States." Nexant Inc. for Ernest Orlando Lawrence Berkeley National Laboratory, January 2015.

Tol, R., and G. Yohe. 2006. "A Review of the Stern Review." World Economics. 7: 233-250.

Toole, G. L., S. Flaim, S. J. Fernandez, J. Bossert, B. W. Bush, B. Neenan. 2006. "Effects of Climate Change on California Energy Security,” SSR Conference, Rep. No. LA-UR-06-0984.

Trenberth, K. E., A. Dai, G. van der Schrier, P. D. Jones, J. Barichivich, K. R. Briffa, J. Sheffield. 2014. "Global Warming and Changes in Drought." Nature Climate Change. 4: 17-22. doi: $10.1038 /$ nclimate2067.

Tennessee Valley Authority. 2014. Climate Change Adaptation Plan. Tennessee Valley Authority, Knoxville, TN. Available at: https://www.tva.gov/file source/TVA/Site\%20Content/About\%20TVA/Guidelines\%20and\%20Reports/S ustainability\%20Plans\%20and\%20Performance/TVA Climate Change Adaptation Plan 2012-2.pdf

Tennessee Valley Authority. 2015. Integrated Resource Plan 2015 Final Report, Tennessee Valley Authority, Knoxville, TN.

Walsh, J., D. Wuebbles, K. Hayhoe, J. Kossin, K. Kunkel, G. Stephens, P. Thorne, R. Vose, M. Wehner, J. Willis, D. Anderson, S. Doney, R. Feely, P. Hennon, V. Kharin, T. Knutson, F. Landerer, T. Lenton, J. Kennedy, and R. Somerville. 2014. Ch. 2: Our Changing Climate. Climate Change Impacts in the United States: The Third National Climate Assessment, J. M. Melillo, Terese (T. C.) Richmond, and G. W. Yohe, Eds., US Global Change Research Program, 19-67. doi: 10.7930/J0KW5CXT. 



\section{APPENDIX A. CALCULATION OF INCREASE IN ELECTRICITY DEMAND DUE TO TEMPERATURE INCREASES}

Increased electricity consumption in response to rising temperatures has a latitudinal dependence (Toole et al., 2006; Allen et al., 2016) and is calculated in two stages. First the percent increase in consumption for a county due to temperature rise is calculated:

$$
J=\left(5.33-0.067 L_{\text {centroid }}\right) * \Delta T
$$

With $J=$ percent increase, $\mathrm{L}_{\text {centroid }}$ equal to the latitude in decimal degrees at the centroid of the county and $\Delta \mathrm{T}$ equal to the change in maximum annual temperature in degrees Fahrenheit.

The new consumption as a result of this increase is calculated:

$$
C=C_{a v} * N *\left(1+\frac{J}{100}\right)
$$

With $C=$ total consumption for the study area, $C_{a v}=$ average customer use and $N=$ number of customers.

Two-meter reference height temperature inputs for these calculations are taken from $4 \mathrm{~km}$ dynamically downscaled (Weather Research and Forecasting model, WRF) historical and worst-case Representative Concentration Pathway scenarios (RCP 8.5) output from the Community Earth System Model (CESM) atthree-hour intervals (Gao et al., 2012) and $0.9^{\circ} \times 1.25^{\circ}$ spatial resolution. The WRF $4 \mathrm{~km}$ data sets are then incorporated as dBASE file tables into a Geographical Information System (GIS) platform and joined to additional energy and infrastructure layers for further analysis. Thus, the calculations combine impacts of rising temperatures, their correlation with increasing electricity consumption, and changes in population to generate maps of future electricity demand.

According to the US Electricity Information Administration (EIA), it can be expected that electricity demand for cooling will increase by a certain factor during a heat wave

(http://www.eia.gov/todayinenergy/detail.cfm?id=7070) and that highest peak demand will occur during this time.

Thus, to estimate increased demand as a result of a worst heat wave, a linear fit to historical peak-toaverage demand ratios (a surrogate measure for the type of generating plants needed to meet electric demand; higher ratios require less baseload, more peaking capacity, a noneconomic trend for a utility) is considered for approximate peak demand for future years in the scenario. Based on PJM ratios of the average to peak for 2012 and its response to the 2012 heat wave, the worst case summertime (June-JulyAug) ratio is approximately 0.41 , and the proportion of summer $\mathrm{kWh}$ to yearly $\mathrm{kWh}$ (given by a local utility) is approximately 0.31 , then the $\mathrm{kWh}$ factor for Jun-Aug increase due to heat waves would be $0.31 \times 0.41=0.13$, and 1.13 can be used as a multiplier for heatwaves during these three months. This increase is on top of the increased demand due to increased temperature for the decade due to climate change. 



\section{APPENDIX B. SCENARIOS, ASSUMPTIONS AND RESULTS OF THE STUDY}

Scenarios and Assumptions

\begin{tabular}{|c|c|c|c|c|c|c|}
\hline & \multicolumn{2}{|c|}{ Heat Wave } & \multicolumn{2}{|c|}{ Drought } & \multicolumn{2}{|c|}{ Population } \\
\hline & Historical & Projected & Historical & Projected & Historical & Projected \\
\hline Scenario & 1993 Event & $\begin{array}{c}\text { RCP 8.5- } \\
2055-2059\end{array}$ & 2007 Event & $\begin{array}{c}\text { RCP } 8.5 \\
2059\end{array}$ & 2010 & 2050 \\
\hline Conditions & $\begin{array}{c}6 \%-7 \% \\
\text { above } \\
\text { historical } \\
\text { average }\end{array}$ & $\begin{array}{c}6 \%-7 \% \\
\text { above } \\
\text { average }\end{array}$ & $\begin{array}{c}\text { Standardized } \\
\text { Precipitation } \\
\text { Values more } \\
\text { extreme than } \\
-3 \text { in } \\
\text { southern } \\
\text { Tennessee; all } \\
\text { but the } \\
\text { northwest } \\
\text { corner of } \\
\text { Tennessee } \\
\text { drier than } \\
\text { normal }\end{array}$ & $\begin{array}{c}\text { Overall area } \\
\text { 1-2 standard } \\
\text { deviations } \\
\text { drier than } \\
\text { normal. This } \\
\text { means wetter } \\
\text { conditions for } \\
\text { more } \\
\text { southern } \\
\text { locations and } \\
\text { drier } \\
\text { conditions for } \\
\text { more } \\
\text { northern ones }\end{array}$ & $\begin{array}{c}2,412,564 \\
\text { total in the } \\
\text { Cumberland } \\
\text { Valley }\end{array}$ & $\begin{array}{c}3,533,984 \\
\text { total in the } \\
\text { Cumberland } \\
\text { Valley }\end{array}$ \\
\hline Methods & $\begin{array}{c}\text { Historical } \\
\text { analogy }\end{array}$ & $\begin{array}{c}\text { Model } \\
\text { projections, } \\
\text { downscaled, } \\
\text { with } \\
\text { historical } \\
\text { analogy } \\
\text { superimposed }\end{array}$ & $\begin{array}{c}\text { SPI with } \\
\text { additional } \\
\text { drying from } \\
\text { historical } \\
\text { temperatures }\end{array}$ & $\begin{array}{c}\text { SPI with } \\
\text { additional } \\
\text { drying from } \\
\text { higher } \\
\text { temperatures }\end{array}$ & LandScan & LandCast \\
\hline Sources & $\begin{array}{c}\text { Lott et al., } \\
1994\end{array}$ & $\begin{array}{l}\text { Lott et al., } \\
1994\end{array}$ & $\begin{array}{c}\text { McKee et al., } \\
1993 ; \\
\text { Grunsky, } \\
1932\end{array}$ & $\begin{array}{c}\text { McKee et al., } \\
\text { 1993; } \\
\text { Grunsky, } 1932\end{array}$ & $\begin{array}{c}\text { Bhaduri } \\
\text { et al., } 2007\end{array}$ & $\begin{array}{c}\text { McKee et al., } \\
2015\end{array}$ \\
\hline
\end{tabular}




\section{Results - impacts to power sector}

\begin{tabular}{|c|c|c|c|c|}
\hline & \multicolumn{2}{|c|}{ Heat Wave } & \multicolumn{2}{|c|}{ Drought } \\
\hline & Historical & Projected & Historical & Projected \\
\hline Electricity Demand & $\begin{array}{c}\text { EIA data state } \\
\text { demand } \\
\text { disaggregated to } \\
1 \text { km cells via } \\
\text { LandScan, } \\
\text { aggregated to } \\
\text { county added heat } \\
\text { wave factor }\end{array}$ & $\begin{array}{c}\text { EIA data } \\
\text { disaggregated to } \\
1 \mathrm{~km} \text { cells via } \\
\text { LandCast, } \\
\text { aggregated to } \\
\text { county, added heat } \\
\text { wave factor over } \\
\text { RCP 8.5 } \\
\text { temperature } \\
\text { increase }\end{array}$ & $\begin{array}{l}\text { No specific change } \\
\text { in demand due to } \\
\text { water shortage }\end{array}$ & $\begin{array}{l}\text { No specific change } \\
\text { in demand due to } \\
\text { water shortage }\end{array}$ \\
\hline $\begin{array}{l}\text { Electricity } \\
\text { Supply }\end{array}$ & $\begin{array}{l}\text { Duke Energy } 2007 \\
\text { power plant shut } \\
\text { down per EPA } \\
\text { regulation caused } \\
\text { blackouts }\end{array}$ & $\begin{array}{l}\text { Potential for } 40 \% \\
\text { reduction in supply } \\
\text { based on shutting } \\
\text { down two large } \\
\text { power plants and } \\
\text { reducing } \\
\text { production at a } \\
\text { third one }\end{array}$ & $\begin{array}{l}2007 \text { drought } \\
\text { reports indicated } \\
\text { that hydropower } \\
\text { production was } \\
\text { only } 50 \%-68 \% \text { of } \\
\text { normal for the } \\
\text { entire year }\end{array}$ & $\begin{array}{l}\text { Potential for } \\
\text { hydropower } \\
\text { production to be } \\
\text { reduced to } 35 \%- \\
60 \% \text { of normal }\end{array}$ \\
\hline Sources & EIA & Toole et al., 2006 & $\begin{array}{l}\text { TVA statements } \\
\text { and press reports }\end{array}$ & $\begin{array}{l}\text { Extrapolation } \\
\text { based on increase } \\
\text { in temperature and } \\
\text { resulting lake } \\
\text { evaporation }\end{array}$ \\
\hline
\end{tabular}




\section{APPENDIX C. METHODS FOR BAYESIAN MODELING OF HYDROPOWER SENSITIVITY TO CLIMATE}

\section{A. DATA SOURCES}

This case study applied a Bayesian modeling approach to generate an empirical model of monthly and annual hydropower generation anomalies in response to anomalies of temperature and streamflow. In developing this approach, data for a number of variables were obtained for 29 hydropower facilities in the TVA region for the years 1970-2013. Data for monthly generation for each facility were obtained from the US DOE's Energy Information Administration (EIA). Monthly generation was also summed for summer months (June, July, August) and the entire year.

The monthly average daily maximum/minimum temperature and monthly total precipitation were collected from the Parameter-elevation Regressions on Independent Slopes Model (PRISM) meteorological dataset (Daly et al. 2002). PRISM provides gridded observations of precipitation and temperature for the entire conterminous US (CONUS) at $1 / 24^{\circ}(\sim 4 \mathrm{~km})$ spatial resolution. For each 8digit US Geological Survey (USGS) Hydrologic Unit Code subbasin (HUC8) within the study domain, area-averaged monthly time series of PRISM temperature and precipitation from 1970 to 2013 were calculated. Monthly data for each year were also averaged (temperature) or summed (precipitation) to generate annual temperature and precipitation estimates.

The 1970-2013 monthly runoff was collected from the USGS WaterWatch runoff (Brakebill et al. 2011) dataset. Derived from the comprehensive USGS National Water Information System (NWIS) gauge observation, WaterWatch runoff is a time series of flow per unit area calculated for each CONUS HUC8. For each HUC8, multiple NWIS gauge stations located within the HUC8 or downstream are used to estimate the runoff generated locally at each $\mathrm{HUC} 8$, with gauge weighting factors determined by joint contributing drainage areas (both gauge-to-HUC8 and HUC8-to-gauge). This approach can effectively integrate streamflow observations from multiple gauge stations as a consistent areal HUC8 runoff measurement with a unit similar to that for precipitation (depth/time). WaterWatch runoff can be considered as a surrogate of natural runoff, and has been used and discussed in several recent hydroclimate studies, including Ashfaq et al. (2013), Beigi and Tsai (2014), and Oubeidillah et al. (2014). Basin runoff calculated via the WaterWatch runoff is also found to be highly correlated to the historical annual hydropower generation (Sale et al. 2012, Kao et al. 2015).

The unregulated flow was calculated based on the total runoff volume from all upstream watersheds. For a given location of interest (i.e., a given hydropower facility), the NHDPlus (EPA and USGS, 2010) river network was used to look up the contribution area of each HUC8 upstream of a site. The HUC8 areas were then multiplied with their corresponding WaterWatch runoff to form estimated monthly time series of unregulated flow. Monthly data for each year were also summed to generate summer and annual streamflow estimates. This flow synthesization method has been used by Kao et al. (2014) to estimate the national hydropower potential from undeveloped stream-reaches.

This process resulted in a database of environmental variables for each hydropower facility on a monthly, summer, and annual level over 43 years as well as the corresponding generation at each facility. However, because temperature, streamflow, and generation vary among individual hydropower facilities, direct comparison of data among facilities is difficult. To facilitate modeling, data for all variables across all facilities were normalized by converting values to anomalies, which were expressed as standard scores (or z-scores). Z-scores were defined using the following equation:

$$
Z=\frac{(X-\mu)}{\sigma}
$$


where $z=$ standard score, $X=$ observed monthly, seasonal, or annual variable value in a for each hydropower facility (1970-2013), $\mu=$ monthly, seasonal, or annual mean over the 43 year time period for each hydropower facility, and $\sigma=$ standard deviation in the monthly, seasonal, or annual mean over the 43 year time period for each hydropower facility. Collectively z-scores capture the inter-annual variability in temperature, streamflow, and generation in a manner that enables comparison over space (i.e., different hydropower facilities) and time.

\section{B. MODELING APPROACH}

The relationships among temperature, streamflow, and generation z-scores were modeled using a graphical modeling approach known as a Bayesian belief network (BBN). A BBN graphically illustrates the conceptual linkages between each variable (dependent and independent). Each variable is represented as a node with multiple states. Hence, each of the nodes for continuous model variables (Tmax, streamflow, and generation) was represented as a series of bins (or states) spanning the distribution of observed values. In order to learn the relationships among the various variables (i.e., "training" the model), an expectation maximization algorithm was applied that calculated the conditional probabilities among each variable and variable state in the network model based on the variables contained within the database. Effectively, the BBN calculated the likelihood of every variable state occurring in response to all the other variable states. Once trained, the model could be used to generate updated estimates of generation anamolies in response to changes in any of the input variables. Although the model output consists of z-scores for generation, z-scores could be converted back into absolute generation using the coresponding monthly or annual mean and standard deviation associated with each facility.

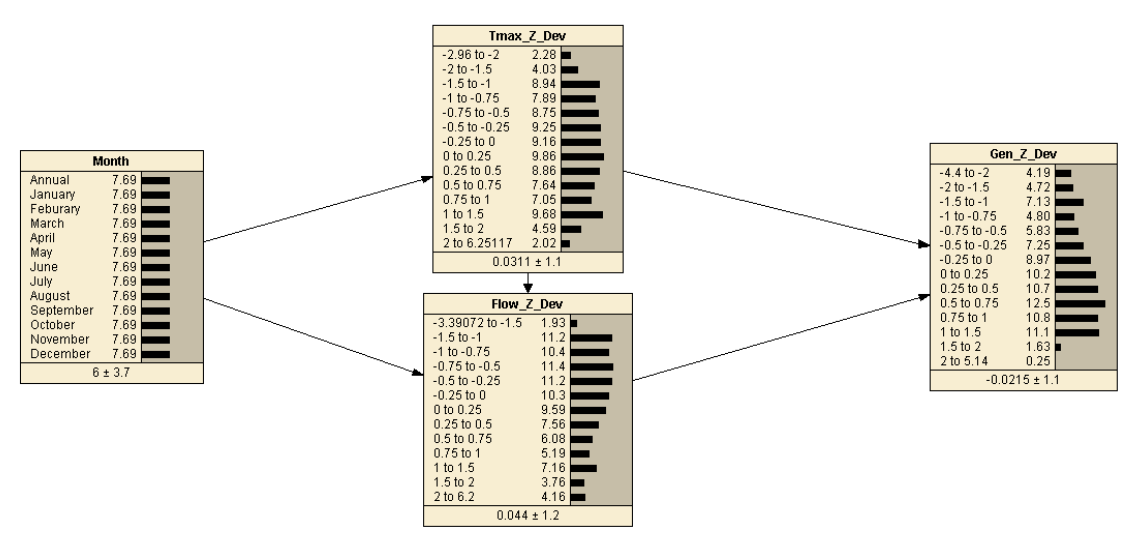

Figure A.1. Graphical representation of the Bayesian model used in the case study to predict hydropower generation anomalies in response to temperature and flow anomalies.

\section{MODEL VALIDATION}

In order to evaluate the performance of the model in estimating hydropower generation responses to variability in temperature and flow, generation z-scores from the model were compared with those observed for each hydropower facility (Figure A.2). Annual total generation estimates from the model explained $91 \%$ of the variance in observed anomalies, indicating a generally high degree of fidelity in the model. Reduced performance was observed for generation anomalies associated with summer (June, July, August) months $\left(\mathrm{r}^{2}=0.58\right)$ and July specifically $\left(\mathrm{r}^{2}=0.61\right)$, due to higher variability in generation anomalies for, or among, individual months. 

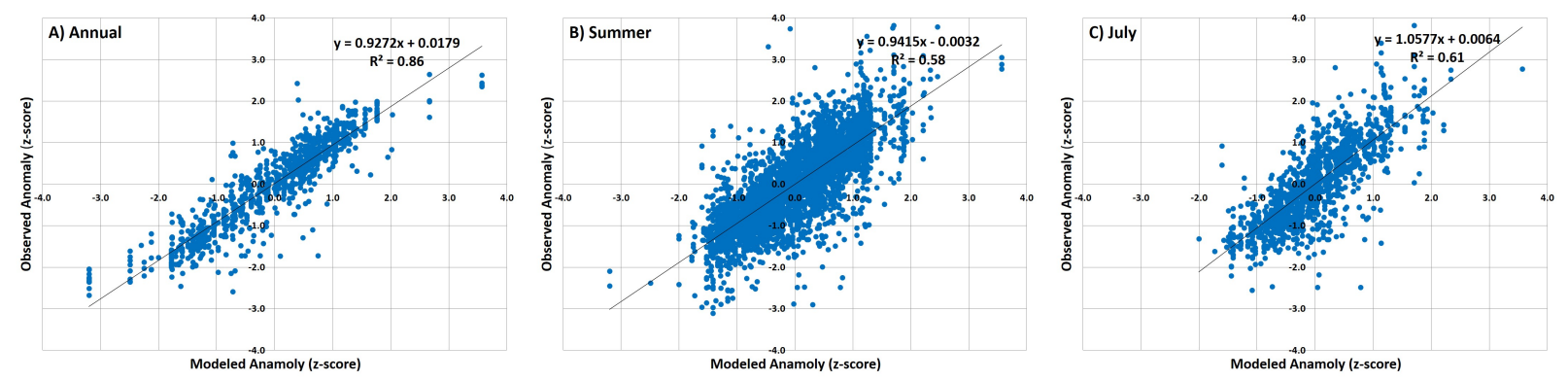

Figure A.2. Regressions of observed hydropower generation anomalies (z-scores) against model estimates. A) annual hydropower generation (1970-2013) for all hydropower facilities in the TVA region. B) monthly hydropower generation (1970-2013) for all hydropower facilities. C) July hydropower generation (1970-2013) for all hydropower facilities.

Because the current case study focuses on net annual and summer generation for all hydropower facilities in the TVA region, validation efforts also focused on comparison of absolute generation estimates from the model for individual facilities and for the region as a whole with observed generation. The model generally performed well in reproducing annual generation for each facility for a given year (as illustrated in Figure A. 3 for 2013 results). Reduced performance was observed for an individual month (as illustrated in Figure A.3 for July, 2013), although results are still comparable. In addition, annual hydropower generation totals for the entire TVA region were compared with observations, resulting in an $r^{2}$ of 0.98 (Figure A.4). A similar regression focusing just on net summer generation results in an $r^{2}$ of 0.92 (Figure A.4). This indicates a high degree of skill in reproducing regional hydropower generation.

\section{CLIMATE CHANGE SCENARIO}

To model the effects of climate change in midcentury on hydropower generation, the BBN model was forced with temperature and rainfall change projected by the CESM and downscaled for the TVA region (Section 2.2, Appendix B). The projections estimate an increase in temperature of approximately $2^{\circ} \mathrm{C}$ $\left(4^{\circ} \mathrm{F}\right)$ and a reduction in precipitation of $20 \%$ over the TVA region. In order to model both short-term variability in the climate as well as long-term climate change, the historical time series (1970-2013) of monthly temperature and streamflow were modified to reflect these projected long-term changes in both temperature and precipitation. These time series were then used as inputs into the Bayesian model. For temperature, the projected $2^{\circ} \mathrm{C}$ increase was added to all observed (1970-2013) monthly, summer, and annual Tmax values for each hydropower facility in each year. This effectively shifted all observed temperatures used in the model by $2^{\circ} \mathrm{C}$, resulting in 43 "model years" of projected temperature consistent with the climate change scenario. These projected temperature values were then converted to z-scores using the projected temperature with the historical mean and standard deviation. 

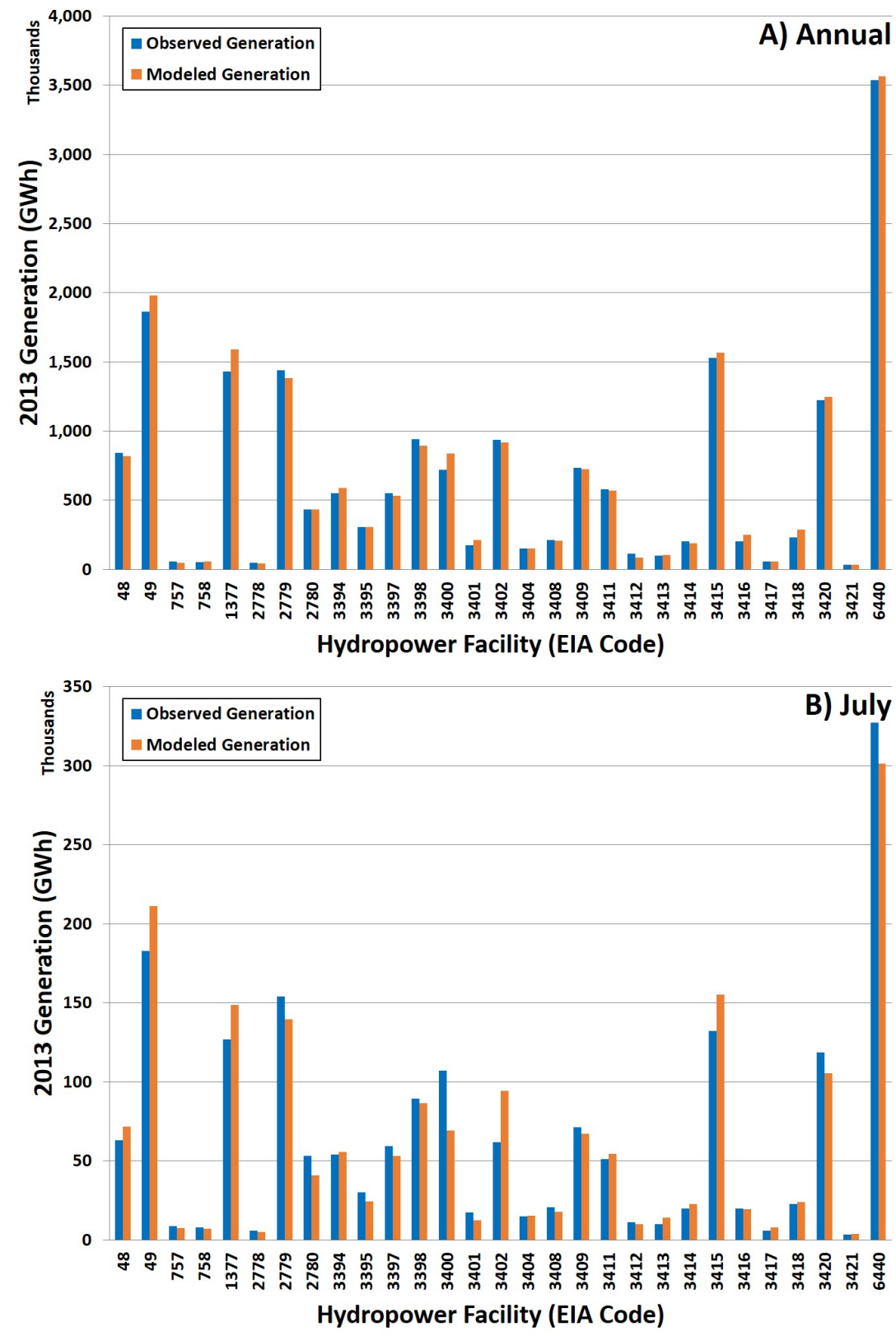

Figure A.3. Comparison of modeled and observed generation for 2013 for individual hydropower facilities. A) annual total generation. B) July monthly generation.

The percentage reduction in precipitation from downscaled climate simulations was converted into a percentage change in streamflow by using observed runoff sensitivities (defined as the percentage reduction in runoff per $10 \%$ reduction in precipitation as previously published in Kao et al., 2016; Naz et al., 2016) for each hydropower facility in the TVA region. Generally, the relationship between precipitation and runoff is a linear one, with reductions (increases) in precipitation associated with proportionally higher reductions (increases) in runoff. The projected change in runoff in each HUC in response to a $20 \%$ reduction in precipitation was applied to all observed (1970-2013) monthly, summer, and annual streamflow values for each hydropower facility in each year. As with temperature, this resulted in 43 "model years" of projected streamflow consistent with the climate change scenario for each 
hydropower facility. As with temperature, these values were expressed as streamflow anomalies (zscores) using the historical monthly mean and standard deviation.
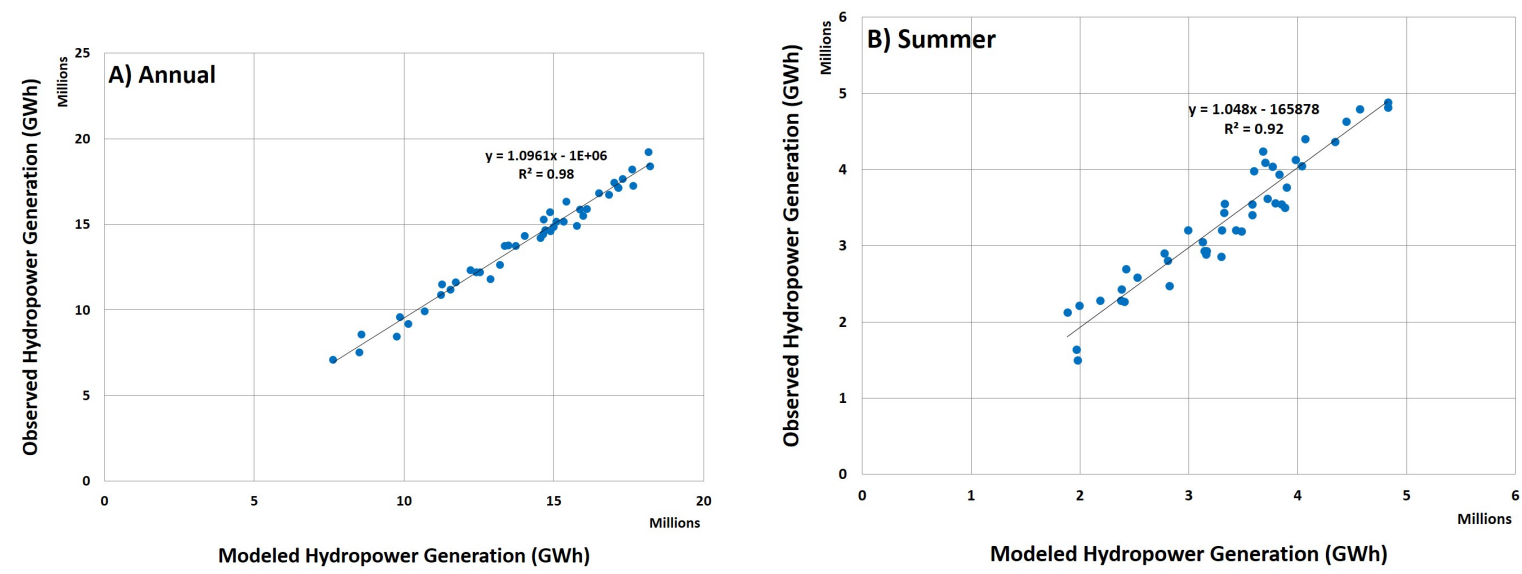

Figure A.4. Regression of observed (A) annual net hydropower generation and (B) June, July, August generation in the TVA region for June, July, August (1970-2013) against Bayesian model estimates of generation for the same time periods.

The projected temperature and streamflow values were used to rerun the model, resulting in 43 model years of generation anomalies (z-scores) for each hydropower facility for the midcentury climate change scenario. Generation z-scores were converted back into absolute anomalies using the following equation:

$$
X=Z * \sigma+\mu
$$

where $X=$ projected monthly, seasonal, or annual generation for each hydropower facility for 43 model years, $z=$ standard score in response to the climate change scenario for 43 model years, $\mu=$ historical (1970-2013) monthly, seasonal, or annual mean over the 43 year time period for each hydropower facility, and $\sigma=$ standard deviation in the historical monthly, seasonal, or annual generation over the 43year time period for each hydropower facility.

In addition to generation, the case study examined the value of generation anomalies using the estimated costs that utilities bear for purchasing power to compensate for shortfalls in generation as a proxy indicator. Using the values reported previously in this report ( $\$ 28 / \mathrm{GWh}$; Table 4$)$, modeled generation anomalies (positive or negative) were converted into dollar figures. Positive generation anomalies are economically advantageous as the additional electricity can be sold to generate revenue. Meanwhile, negative anomalies represent a cost as less electricity is being generated than normal, which represents a missed opportunity and could require shortfalls to be made-up through other means.

This approach used the climate change scenario $(+2 \mathrm{C},-20 \%$ precipitation) to capture the effects of longterm shift in the climate while using the 43 years of observations to capture the effects of interannual variability in the climate (assuming future variability is consistent with past variability). Hence, the projected impacts on generation and generation costs effectively represent 43 model years or a 43member ensemble of midcentury generation impacts. 
